TITLE:

\title{
Shallow Subsurface Structure in the Hualien Basin and Relevance to the Damage Pattern and Fault Rupture during the 2018 Hualien Earthquake
}

\section{$\operatorname{AUTHOR}(S)$ :}

Yamada, Masumi; Cho, Ikuo; Kuo, Chun-Hsiang; Lin, CheMin; Miyakoshi, Ken; Guo, Yujia; Hayashida, Takumi; ... Mori, Jim; Yen, Yin-Tung; Kuo, Keng-Chang

\section{CITATION:}

Yamada, Masumi ...[et al]. Shallow Subsurface Structure in the Hualien Basin and Relevance to the Damage Pattern and Fault Rupture during the 2018 Hualien Earthquake. Bulletin of the Seismological Society of America 2020, 110(6): 2939-2952

\section{ISSUE DATE:}

2020-12

\section{URL:}

http://hdl.handle.net/2433/267451

\section{RIGHT:}

This is a postprint of the article, which has been published in final form at https://doi.org/10.1785/0120200063.; The fulltext file will be made open to the public on 22 SEPTEMBER 2021 in accordance with publisher's 'Terms and Conditions for Self-Archiving'.; This is not the published version. Please cite only the published version. この論文は出版社版であり ません。引用の際には出版社版をご確認ご利用ください。 


\section{Shallow Subsurface Structure in the Hualien Basin and Relevance to the Damage Pattern and Fault 3 Rupture During the 2018 Hualien Earthquake} Masumi Yamada ${ }^{1}$, Ikuo $\mathrm{Cho}^{2}$, Chun-Hsiang Kuo ${ }^{3}$, Che-Min $\mathrm{Lin}^{4}$, Ken Miyakoshi $^{5}$, Yujia Guo ${ }^{5}$, Takumi Hayashida ${ }^{6}$, Yasuhiro Matsumoto ${ }^{7}$, Jim Mori $^{1}$, Yin-Tung Yen ${ }^{8}$, Keng-Chang Kuo ${ }^{9}$

M. Yamada, Kyoto University, Uji, Gokasho, 611-0011, Japan

${ }^{1}$ Disaster Prevention Research Institute, 
X - 2 YAMADA ET AL: SHALLOW SUBSURFACE STRUCTURE IN HUALIEN BASIN

4 Abstract. The 2018 Hualien earthquake (Mw6.4) generated a large peak-

${ }_{5}$ to-peak velocity of over $2 \mathrm{~m} / \mathrm{s}$ with a period of $3 \mathrm{~s}$ at the south end of the

6 Milun fault, which resulted in the collapse of five buildings. To investigate

7 the shallow subsurface soil structure and evaluate possible effects on the ground

s motion and building damage, we performed microtremor measurements in

9 the Hualien basin. Based on the velocity structure jointly inverted from both

10 Rayleigh-wave dispersion curves and microtremor Horizontal-to-Vertical (H/V)

${ }_{11}$ spectral ratio data, we found that the shallow subsurface structure gener-

${ }_{12}$ ally deepens from west to east. Close to the Milun fault, the structure be-

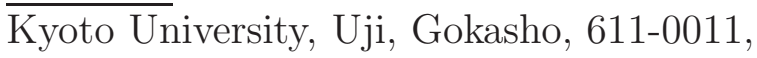

Japan

${ }^{2}$ National Institute of Advanced

Industrial Science and Technology, Japan

${ }^{3}$ National Central University, Taiwan

${ }^{4}$ National Center for Research on

Earthquake Engineering, Taiwan

${ }^{5}$ Geo-Research Institute, Japan

${ }^{6}$ Building Research Institute, Japan

${ }^{7}$ Kozo Keikaku Engineering, Japan

${ }^{8}$ Sinotech Engineering Consultants, Inc.,

Taiwan

${ }^{9}$ Kaohsiung university of Science and

Technology, Taiwan 
${ }_{13}$ comes shallower which is consistent with faulting during the 2018 earthquake

14 and the long-term tectonic displacement. There is no significant variation

15 for the site conditions in the north-south direction that can explain the large

${ }_{16}$ peak ground velocity in the south. As a result of the dense measurements

${ }_{17}$ in the heavily damaged area, where three high-rise buildings totally collapsed,

${ }_{18}$ these locations have the AVS30 values (average S-wave velocity of the up-

19 per $30 \mathrm{~m}$ ) are relatively high compared to the more distant area from the

${ }_{20}$ Meilun river. This is somewhat unusual since lower AVS30 values indicat-

${ }_{21}$ ing softer ground conditions are expected close to the river. We did not find

22 any characteristic subsurface soil structure which may contribute to the build-

${ }_{23}$ ing collapses. The large $3 \mathrm{~s}$ pulse was probably generated by source effects,

${ }_{24}$ rather than subsurface soil amplification. 


\section{$\mathrm{X}-4$ \\ YAMADA ET AL: SHALLOW SUBSURFACE STRUCTURE IN HUALIEN BASIN}

\section{Introduction}

The 2018 Hualien earthquake in Taiwan (Mw 6.4, at 23:50:43, February 6, 2018, local

26 time) showed a very complex fault structure. The moment tensor mechanism shows a

${ }_{27}$ substantial non-double couple component (e.g. USGS website, see Data and Resources

${ }_{28}$ Section), which suggests there were multiple fault geometries. The source models in the

29 seismic waveform and geodetic inversions [e.g. Lee et al., 2019; Huang and Huang, 2018;

30 Lo et al., 2019] use multiple fault planes to explain the observed data.

31

The Milun fault, one of the fault structures causing the earthquake, runs in a north32 south (NS) direction through the center of the Hualien basin (Figure 1). This fault 33 previously ruptured on October 22, 1951, causing a $\mathrm{M}_{L}$ 7.1-7.3 earthquake [Lo et al., 2012].

${ }_{34}$ At that time, surface rupture appeared in downtown Hualien [Huang et al., 2019] from the

${ }_{35}$ Qixingtan coast, through the west side of Meilun Mountain, to the old port (see Data and

${ }_{36}$ Resources Section). This fault was likely reactivated during the 2018 Hualien earthquake

${ }_{37}$ [Huang et al., 2019; Lin et al., 2019; Wu et al., 2019a]. Source models suggest that the

${ }_{38}$ fault dips to the east, and the slip is thrust movement with a left-lateral component [Lee

s9 et al., 2019; Kuo-Chen et al., 2019; Lo et al., 2019].

40 There was an unusual pattern in the damage of the high-rise buildings. In Hualien city,

${ }_{41}$ four buildings totally collapsed with story failure and one totally collapsed without story

${ }_{42}$ failure. All of these structures were located very close to the Milun fault based on the

${ }_{43}$ Reconnaissance report by the National Center for Research on Earthquake Engineering

${ }_{44}$ (NCREE) (see Data and Resources Section). Researchers have debated the relationship

${ }_{45}$ between the observed damage distribution and the fault rupture [e.g. Huang et al., 2019;

${ }_{46}$ Lin et al., 2019].

${ }_{47}$ Ground motions at a site are influenced by the source, travel path, and local site char-

48 acteristics. One possible explanation is that the building damage resulted from ground 
49 motion amplification due to local soil structure. In this study, we performed microtremor measurements to investigate the shallow subsurface soil structure in the Hualien basin.

${ }_{51}$ We set a measurement line along a northwest-southeast section of the Hualien basin across

${ }_{52}$ the fault to see the difference in the shallow velocity structure. We also made measure-

${ }_{53}$ ments in the heavily damaged area where three high-rise buildings collapsed. Based on

${ }_{54}$ the inverted subsurface velocity structure, we will discuss the relationship between the 55 subsurface soil structure and building damage.

\section{Strong Motion and Building Damage}

${ }_{56}$ The strong motions during the 2018 Hualien earthquake were recorded by the dense ${ }_{57}$ seismic networks of the Central Weather Bureau (CWB) in Taiwan [Shin et al., 2013] and ${ }_{58}$ the P-Alert Strong Motion Network [Wu et al., 2019b]. Downtown Hualien is located in a narrow basin (width of several kilometers) between the Central Mountain Range and the

${ }_{60}$ Pacific Ocean (Figure 1). The Milun fault runs in a NS direction through the center of ${ }_{61}$ the Hualien basin. Geology of the west side of the Milun fault is alluvium, and east side 62 of the fault consists of either conglomerate or sandy layer.

There are 20 stations in the Hualien basin with average spacing of about $1 \mathrm{~km}$. Figure ${ }_{64} 2$ shows the velocity records at the strong motion stations on the east and west sides of ${ }_{65}$ the fault from north to south. The locations of the seismic stations are shown in Figure 3.

${ }_{66}$ The main pulse has a period of $3 \mathrm{~s}$, and the phases of the waveforms are rather different ${ }_{67}$ between the east and west sides of the fault for the NS component. The arrival of this ${ }_{68}$ large pulse is about $5 \mathrm{~s}$ later than the $\mathrm{S}$-wave arrival from the hypocenter, which suggests ${ }_{69}$ the source of this pulse is away from the hypocenter.

70 The acceleration response spectra in Figure 4 show different spatial patterns depending ${ }_{71}$ on the period. The distribution of the response spectra at $0.5 \mathrm{~s}$ is relatively homogeneous 


\section{$\mathrm{X}-6$

72 over the basin, and the stations on the western side of the basin (HWA048 and HWA028)

${ }_{73}$ show slightly higher values. This suggests that the western side of the basin consists of

${ }_{74}$ thinner deposits, which may amplify the shorter period ground motion. On the other

75 hand, the long-period ground motions with periods of 2-3 s were strongly amplified near

76 the southern end of the Milun fault.

77 A damage survey of the high-rise buildings was carried out in the Hualien basin by

78 Kuo et al. [2018]. Note that the definition of high-rise buildings in Taiwan is 10 or more

${ }_{79}$ floors. There are five buildings rated as damage rank 5 according to the damage scale

so of Hsiao et al. [1999], i.e., complete destruction, but most of the high-rise buildings were

${ }_{81}$ undamaged or sustained minor damage [Kuo et al., 2018]. The locations of the heavily

${ }_{82}$ damaged buildings are shown in Figure 3. It is interesting that the heavily damaged

83 buildings are all very close to the fault surface rupture, but not concentrated near the

${ }_{84}$ southern end of the Milun fault, where the large peak ground velocity was recorded

${ }_{85}$ (around the station W028).

\section{Microtremor Survey}

We performed microtremor surveys in the Hualien basin from October 20 to 26, 2018.

${ }_{87}$ We used ten seismometers (JU410) made by Hakusan Corporation to perform array mea-

${ }_{88}$ surements. The JU410 instrument includes 3 component acceleration-type sensors, a

s9 logger, and a battery, in casing. The sampling frequency was set to $200 \mathrm{~Hz}$ with the

90 high-cut filter set at $80 \mathrm{~Hz}$.

We performed small (scale of about $10 \mathrm{~m}$ ) and large (scale of a few hundred meters) array measurements. The small array measurements were performed with 5 seismometers

${ }_{93}$ in arrays consisting of a regular triangle with a radius of $0.6 \mathrm{~m}$, and two seismometers 94 set further apart along the line of the center of the triangle (see Figure $5(\mathrm{~d})$ ). The 
${ }_{95}$ distance of the two seismometers from the triangle is about 10 and $15 \mathrm{~m}$. We performed these array measurements at 64 locations shown in Figure 3. Locations of the small arrays were selected for three purposes. First, we measured along the line X-Y with a ${ }_{98}$ spacing of 50-200 $\mathrm{m}$ to obtain an east-west (EW) profile of the Hualien basin. We also 99 performed 22 measurements within the heavily damaged area D in Figure 3 to evaluate the 
$\mathrm{X}-8$

${ }_{120}$ that obtained by a broadband velocity sensor at the frequency $0.2-20 \mathrm{~Hz}$ [Kuo et al., 121 2019] (Figure S1).

\section{Method}

The obtained microtremor data were processed with the following methods.

123

124

125

\section{H/V Spectral Ratios}

The $\mathrm{H} / \mathrm{V}$ spectral ratios [Nakamura, 1989] at each observation point were computed from the three-component microtremor waveforms. First, we split the time series into windows of 4096 points (20.48 s), with a $50 \%$ overlap; this resulted in approximately 50 windows for each measurement. This window length should be sufficient to capture low-frequency information for $\mathrm{H} / \mathrm{V}$ in the range of $0.1-0.5 \mathrm{~Hz}$. Before transforming the time windows into the frequency domain, a weighted Hanning window was applied. Windows with obvious transient noise were excluded from the analysis. A Fast Fourier Tranform (FFT) was applied to each individual time window to obtain the Fourier amplitude spectrum. Those spectra were then smoothed by a Konno-Ohmachi filter [Konno and Ohmachi, 1998] with a smoothing coefficient value $b=20$. The horizontal component is defined as the geometric mean of the two components [Bard et al., 2008]. We visually checked that the peak frequencies of the two components were very similar. We used five seismometers at each observation point, and consequently, we averaged the five $\mathrm{H} / \mathrm{V}$ spectral ratios. We resampled the $\mathrm{H} / \mathrm{V}$ curves with 64 logarithmically spaced samples between 0.25 and $10 \mathrm{~Hz}$. These resampled curves were used as input to the inversion analysis.

\section{Phase Velocity}

In order to obtain the Rayleigh-wave phase velocities, we applied the spatial autocorrelation (SPAC) method [Aki, 1957] to the vertical-component microtremor array data. 
${ }_{143}$ In the determination of the phase velocities, power and cross spectral densities were es-

timated with the techniques of both smoothing and ensemble averaging in the frequency domain [Bendat and Piersol, 2010]. The waveforms of each small array were split into windows of $10.24 \mathrm{~s}$ duration with $50 \%$ overlap, this resulted in approximately 100 windows per site, and a weighted Hanning window was applied. We apply a Fast Fourier Transform (FFT) to obtain magnitude-squared FFT spectra, which were then smoothed using a Parzen window with a bandwidth of $0.3 \mathrm{~Hz}$. The smoothed spectra were averaged at each frequency (i.e., ensemble average).

A shorter window length was used to process the microtremor array data than for $\mathrm{H} / \mathrm{V}$ spectral analysis because the focus was on frequencies greater than a few hertz. It also enables stacking a large number of data segments, which contributes to improving the robustness. A phase-velocity dispersion curve may exhibit abrupt changes in frequencies higher than $10 \mathrm{~Hz}$ at a site with thin sedimentary layers. Without a priori information on the local site condition, frequency-dependent windowing sometimes causes over smoothing in high frequency. Therefore, we used the Parzen window with a bandwidth of $0.3 \mathrm{~Hz}$ to avoid over-smoothing at higher frequencies.

The calculated spectral densities were used to calculate the real part of the complex coherencies (SPAC coefficients) The obtained Rayleigh-wave phase velocities were resampled with logarithmically spaced samples between a few (1.1-3.0 Hz depending on sites) to $20 \mathrm{~Hz}$ and used for the subsequent inversion analysis.

\section{Joint Inversion for the S-wave Velocity Structure}

We inverted for the S-wave velocity (Vs) structure using the Rayleigh-wave phase velocities and $\mathrm{H} / \mathrm{V}$ spectral ratios following the method of Arai and Tokimatsu [2005]. First, we constructed the initial model from the PS logging data at the surrounding strong motion stations (see Data and Resources Section). The logging data at the stations west of 
${ }_{168}$ the fault consist of three major layers: 1) very silty or clayey sand (Vs $\left.\sim 200 \mathrm{~m} / \mathrm{s}\right), 2$ ) silty

169 gravels or well-graded gravels $(\mathrm{Vs} \sim 300 \mathrm{~m} / \mathrm{s})$ and 3) silty sand or silts with very fine sand

${ }_{170}(\mathrm{Vs} \sim 350 \mathrm{~m} / \mathrm{s})$. We used these three layers for the top three layers of the initial model

${ }_{171}$ (Table 1). The logging data at the stations east of the fault include a silty gravel layer

172 with higher velocity $(\mathrm{Vs} \sim 600 \mathrm{~m} / \mathrm{s})$ which we used as a fourth layer of the initial model.

We obtained a one-dimensional velocity structure model at each observation point by iteratively improving the above initial model to explain the observed phase velocities and $\mathrm{H} / \mathrm{V}$ spectral ratios. During the inversion procedure, the thickness and the S-wave velocity in each layer were set to be unknown parameters. The density was estimated based on the empirical relationship with the P-wave velocity (Vp) [Gardner et al., 1974] and Vp 
At the large array sites, following Foti et al. [2018], the maximum depths of investigation were assumed to be the maximum aperture of the arrays or less (i.e., several hundreds of meters). At the small array sites, on the other hand, the maximum depths of investigation were assumed to be several tens of meters, or a few times larger than the maximum array aperture. This expectation is based on our experience that small arrays have better relative resolution as compared to large arrays. As well, a joint analysis of phase velocity and $\mathrm{H} / \mathrm{V}$ spectral data seems more effective for smaller arrays from the perspective of extending the analysis to low-frequency ranges.

\section{Analysis of Large Array Data}

It was difficult to construct a detailed initial model to the depths corresponding to the large array surveys, due to the lack of data constraining geologic/geotechnical parameters at depth. Therefore, the large array data were analyzed by a method similar to that for the small arrays with the following difference. The duration and number of data segments used for the ensemble average were $20.48 \mathrm{~s}$ and 92 or $40.96 \mathrm{~s}$ and 53, respectively, depending on the array size. The bandwidth of the Parzen window was set to 0.1 or $0.3 \mathrm{~Hz}$. We selected these values to avoid over smoothing of the spectra at the target frequency. The phase velocity in the low frequency $(<2 \mathrm{~Hz})$ domain was obtained by reading zero-crossing points of the SPAC coefficients [Ekström et al., 2009].

Unlike the small arrays which have relatively more information on the shallow structure, the information to the depths corresponding to the large array is limited. Therefore, we constructed an initial model empirically [Ballard Jr, 1964]. The initial models (number of layers and Vs) is updated by an empirical Bayesian approach [Cho and Iwata, 2019] to better explain the phase velocity dispersion curve. It enables flexible modeling of shallowto-deep structure by automatically determining the number of layers based on the Bayes 
${ }_{217}$ factor. We inverted only the S-wave velocities for multiple thin layers, with the thickness ${ }_{218}$ of each layer fixed to a specific value.

\section{Results}

\section{H/V Spectral Ratios}

Figure 5(a) shows the peak frequencies and peak amplitudes of the $\mathrm{H} / \mathrm{V}$ spectra. The results reflect the local heterogeneous velocity structure, on a macroscopic scale, with a higher frequency peak (about $2 \mathrm{~Hz}$ ) on the western mountain side (e.g., around the station HWA048), and a lower frequency peak (about $1 \mathrm{~Hz}$ ) around the Meilun river delta. The east side of the Milun fault, which is close to the coast (e.g., around the station HWA009), is at a slightly higher altitude and the peak frequency is higher than the river sediment area (e.g., around the station HWA019).

Figure 6(a) shows the H/V spectra for the EW section along the X-Y line in Figure 3. The peak frequency is higher on the west side of the basin (at $121.58^{\circ}$ about $2 \mathrm{~Hz}$ ), and gradually decreases to the east (at $121.59^{\circ}$ about $1 \mathrm{~Hz}$ ). The spectra at the floodplain of the Milun river $\left(121.605^{\circ}-121.61^{\circ}\right)$ have a very large amplitude peak at a frequency of $1 \mathrm{~Hz}$, and the amplitude at higher frequencies is very small (Figure 5(a)). This may indicate a strong velocity contrast in the subsurface structure. The east side of the Milun fault shows relatively flat spectra $\left(121.612^{\circ}-121.615^{\circ}\right)$.

\section{Phase Velocity}

We obtained four phase velocity dispersion curves from the different sensor spacings in the small array measurement: a regular triangle with a radius of $0.6 \mathrm{~m}$ and pairs of sensors with the distances of about $5 \mathrm{~m}, 10 \mathrm{~m}$, and $15 \mathrm{~m}$. These curves were connected to obtain a single phase velocity curve across the frequency range of our interest (i.e., a 
${ }_{239}$ few to $20 \mathrm{~Hz}$ ). An example of the phase velocity curves at the station HWA011 is shown 240 in Figure $7(b)$.

Figure 5(b) shows the distribution of the minimum phase velocity of the dispersion curve, which generally corresponds to the S-wave velocity of the shallowest layer. The east side of the Milun fault and west of the railway, clearly shows higher S-wave velocity, ${ }_{244}$ at about $250 \mathrm{~m} / \mathrm{s}$. The S-wave velocity is lower on the west side of the Milun fault at ${ }_{245}$ about $150-200 \mathrm{~m} / \mathrm{s}$, probably due to the deposits of the Meilun river.

Figure 5(c) shows the distribution of the AVS30 determined by directly reading the ${ }_{247}$ Rayleigh-wave phase velocity, corresponding to the wavelength of $40 \mathrm{~m}$. It is well known that the phase velocity at the wavelength of $40 \mathrm{~m}$ is a good approximation of AVS30 [Brown et al., 2000; Konno and Kataoka, 2000; Martin and Diehl, 2004; Cho et al., 2008;

${ }_{250}$ Albarello and Gargani, 2010]. The figure indicates that AVS30 values east of the fault are ${ }_{251}$ greater than $300 \mathrm{~m} / \mathrm{s}$, whereas west of the fault the values are mostly smaller than 300 ${ }_{252} \mathrm{~m} / \mathrm{s}$.

Figure 8 shows the phase velocity curves, including relatively low frequencies obtained ${ }^{254}$ from measurements of the large arrays on the east and west sides of the fault. The phase ${ }_{255}$ velocity curves for the two sides of the fault are quite different in the frequency range at ${ }_{256} 1-10 \mathrm{~Hz}$, indicating that the S-wave velocity of the shallow layers is greater on the east ${ }^{257}$ side of the fault compared to the west side of the fault. On the other hand, there may be ${ }_{258}$ little difference in the deeper structure.

\section{${ }^{259} \quad$ Inverted Velocity Structure}

We inverted for the velocity structure from the obtained phase velocity curves. An example of the data fitting at the HWA011 station is shown in Figure 7. The black and gray curves show the observed and calculated data based on the optimal velocity structure, respectively. The fits for both $\mathrm{H} / \mathrm{V}$ spectra and phase velocity curves are reasonably good. 
${ }_{264}$ By inverting those two quantities simultaneously, we were able to obtain the velocity structure to the depth corresponding to the $1 \mathrm{~Hz}$ peak of $\mathrm{H} / \mathrm{V}$ spectrum (about $50-75 \mathrm{~m}$

${ }_{266}$ assuming Vs 200-300 m/s). We visually checked the fit of all other sites and confirmed

${ }_{267}$ that the velocity models explained the observed data.

\section{Hualien Basin Profile}

Figure 6(b) shows the velocity structure of the EW section along the X-Y line in Figure 3. There is a large difference between the east and west sides of the Milun fault. The thickness of the first and second layers $(\mathrm{Vs}<300 \mathrm{~m} / \mathrm{s})$ gradually increases from west to east, but suddenly decreases at the location of the fault. This change is much larger than the change of the topography at the ground surface. There is not a large difference in the thickness of the first layer, but Vs is very low $(<200 \mathrm{~m} / \mathrm{s})$ on the west side of the fault, which is assumed to be a floodplain of the Meilun river.

\section{Deep Structures}

Figure 8(b) shows the inverted velocity structure for the phase velocity curves obtained from the large array measurement. The S-wave velocity of the upper layers $($ depth $<500$ $\mathrm{m}$ ) is well resolved and greater on array E than on the array W. The greater Vs east of the fault is consistent with the Hualien basin profile shown in Figure 6(b). The deeper structure (depth $>500 \mathrm{~m}$ ) does not seem to have a large difference between the two arrays.

PS logging data at the Strong Motion Stations

To evaluate the accuracy of the velocity estimation, we compared the estimated velocity structure with the borehole PS logging data at the strong motion stations (Figure 9). We have 7 stations with shallow velocity profile logging data (about $30 \mathrm{~m}$ depth, see Data and Resources Section) and 1 station with deep logging data to $200 \mathrm{~m}$ [Okamoto et al., 1998]. Our results demonstrate good agreement between the obtained Vs depth profile 
289 and the available logging data, except for the HW019 station, where logging data indicate

${ }_{290} \mathrm{Vs}>600 \mathrm{~m} / \mathrm{s}$ at $15 \mathrm{~m}$, whereas the inverted structure shows a Vs of only $350 \mathrm{~m} / \mathrm{s}$ at the

291 same depth.

${ }_{292}$ Phase velocity curves estimated from the triangle array and linear arrays

${ }_{293}$ In order to verify the reliability of the linear array measurements, we compared phase

294 velocity curves obtained from the triangle and linear arrays at the site of the large array

${ }_{295} \mathrm{~W}$, where we have triangle arrays with radii of $0.6,9$, and $17 \mathrm{~m}$ and 2-point linear arrays

${ }_{296}$ with distances of 5, 10, and $15 \mathrm{~m}$. Figure 10(a) shows the phase velocity curves estimated

${ }_{297}$ from these arrays. The phase velocity curves estimated from the linear arrays are within

${ }_{298} \pm 20 \%$ of those estimated from triangle array results. At each site with a small array, we

299 used a triangle array, together with linear arrays, so that we can verify the reliability of

300 the linear arrays at high frequency. For example, as demonstrated in Figures 10(b) and

301 10(c), the results at the strong motion stations show good agreement between the phase

302 velocity curves estimated from the linear and triangle arrays. These results suggest that the wavefield is close to "isotropic", in the sense that it is appropriate to use the SPAC

304 method at these sites.

${ }_{305}$ It is true that an isotropic wavefield is preferable for the SPAC analysis, in particular, when we use a linear array with 2 sensors (2-point array). However, it does not mean that a completely isotropic field is needed to obtain the dispersion curve. A two-point array has 
$\mathrm{X}-16$ YAMADA ET AL: SHALLOW SUBSURFACE STRUCTURE IN HUALIEN BASIN

${ }_{314}$ array measurements and revealed that mostof the 2-point arrays analyzed had an error ${ }_{315}$ of $<20 \%$. The phase velocity curves in Figure 10 suggest that the effect of an anisotropic 316 wavefield was relatively small in at least the frequency range of these arrays.

${ }_{317}$ Note that the 2-point array may not be suitable for certain situations. For example, 318 we cannot use the 2-point array for a wavefield with strong directional components (e.g., 319 vicinity of factories which produce strong seismic noise). The regular polygon array is ${ }_{320}$ always preferable as long as there is enough space and equipment. When we cannot avoid ${ }_{321}$ using 2-point arrays, we need to check the isotropy of the wavefield for the SPAC analysis.

\section{Discussion}

\section{${ }_{322}$ Subsurface velocity structure and regional tectonics}

The Hualien basin is associated with the collision of the Philippine Sea plate and ${ }_{324}$ Eurasian plate [Angelier, 1986; Yu et al., 1997]. The basin is long and narrow in the ${ }_{325}$ NS direction. The east side of the Milun fault (Hualien tableland) has a higher altitude ${ }_{326}$ than the west side of the fault, and the Meilun river runs along the fault (Figure 3).

Although there is a general deepening of the shallow structure from west to east, our results show a large difference in the opposite sense across the Milun fault. The section 334 fault.

335 
${ }_{337}$ uplifted during the mainshock [Lee et al., 2019; Huang and Huang, 2018; Lo et al., 2019].

${ }_{338}$ Such uplift might accumulate on the east side of the fault over numerous earthquakes,

зз9 which results in the higher altitude. The west side of the fault becomes relatively lower,

340 and sedimentary deposits form the low S-wave velocity layers near the surface.

${ }_{341}$ Note that Figure 6(b) was estimated from the surface wave data, and the heterogeneous ${ }_{342}$ structure in the horizontal direction is affected by the resolution depending on the wave-

${ }_{343}$ length. That is, since the deeper part of the figure was estimated by waves with longer ${ }_{344}$ wavelengths, it may have a limited resolution to capture the sharp change of the velocity 345 structure in the horizontal direction.

\section{Relationship to the Pulse-like Strong Motions}

There was a characteristic pattern in the strong motion distribution in the Hualien basin. The velocity waveforms show a large pulse-like waveform with a period of $3 \mathrm{~s}$ (Figure 2) and large amplitudes at the southern end of the Milun fault (Figure 4(d)). This was observed on both the eastern and western sides of the fault. Ground motions are influenced by the source, path, and site characteristics. One possible explanation is the large velocity pulse with $3 \mathrm{~s}$ period was generated by the local site response.

The results of our survey show that there is no significant shallow subsurface difference at the southern end of the Milun fault in comparison to the northern end, which could explain the distribution of building damage in this region. Figure 11 shows the S-wave ${ }_{356}$ velocity structure in the NS direction along the Meilun river (along the Z-Z' section in Figure 3). The section shows a horizontally layered structure and no significant change along the Milun fault. This is consistent with the tectonic regime of the Hualien region. Due to the EW compressional tectonics, there is a substantial change of velocity structure in the EW direction (Figure 6(b)), but little variation in the NS direction (Figure 11). 
Based on our large array measurements, Vs reached $750 \mathrm{~m} / \mathrm{s}$ at a hundred meter depth.

362 Suppose the $3 \mathrm{~s}$ velocity pulse was the response of the local velocity structure, then 363 we would need a strong velocity contrast with a thick low-velocity deposit (e.g. $450 \mathrm{~m}$

364 thickness assuming Vs $600 \mathrm{~m} / \mathrm{s}$ ). Figure S2 shows the transfer functions for the velocity

365 structures estimated from the large array measurements based on the one-dimensional 366 elastic site response [Haskell, 1960]. The predominant frequencies for the array $\mathrm{E}$ and $\mathrm{W}$ 367 are about 0.8 and $0.5 \mathrm{~Hz}$, respectively.

${ }_{368}$ The peak period of the ground motion during the mainshock was $3 \mathrm{~s}$, but our data 369 showed that it was difficult to explain this period from the subsurface soil amplification at 370 least for the linear response. Figure 2 shows the pulse-like ground motions are commonly ${ }_{371}$ observed at most stations, but the phase seems to be different on the east and west sides 372 of the fault. The displacement records after the integration of these data show the static 373 offset at this time [Kuo et al., 2019]. Kuo et al. [2019] concluded that this pulse-like 374 ground motion might have been caused by the asperity, forward directivity amplification, 375 and radiation pattern rather than the local site effect. Other studies also explain this 376 3-s pulse by source effects, such as rupture directivity and near-field waveform from the ${ }_{377}$ shallow fault segment with a large slip [Wen et al., 2019; Miyakoshi et al., 2019]. Therefore, ${ }_{378}$ although we cannot exclude the possibility of the non-linear response of the subsurface soil structure or 2D/3D basin effects [Kawase, 1996], our results suggest that the 3 s velocity

380 pulse was more likely generated by a source effect, rather than the local site response.

381

\section{Relationship to the Building Damage}

There were five buildings which were completely destroyed during the mainshock, and all of them were located very close to the fault surface rupture. It might be expected that the large velocities with $3 \mathrm{~s}$ period at the southern end of the Milun fault might be responsible for the damage to high-rise buildings, but the spatial pattern of long-period 
386 ground motions does not match the overall distribution of collapsed buildings (Figure

$\left.{ }_{387} 4(\mathrm{~d})\right)$. We focused on the heavily damaged area D in Figure 3, where three buildings

388 collapsed, and performed dense microtremor measurements to investigate the possible

${ }_{389}$ effect of local site characteristics on the damage of the structures.

390 Kuo et al. [2018] performed a damage survey for the high-rise buildings with 10 or more stories in that area. As shown in Figure 12, the buildings close to the river have more severe damage. Therefore, there is a debate on whether the reason for the collapsed ${ }_{393}$ buildings is the subsurface amplification due to the deposits of the river. The AVS30 394 distribution obtained from our survey showed slightly higher values close to the river (Figure 12). This suggests that the shallow layers close to the river are unexpectedly hard compared to those farther from the river. This is probably due to the dip-slip faulting, as we have seen in Figure 6(b). The first and second layers with low Vs have become thinner on the east side compared to the west side of the fault because of the vertical deformation.

The natural period of the reinforced concrete structure can be approximated by $0.07 \mathrm{~N}$ ${ }_{400}$ (where $\mathrm{N}$ is the number of the floors) [Hong and Hwang, 2000]. We also performed ${ }_{401}$ microtremor measurements at the two 13-floor buildings, and their natural periods were ${ }_{402} 0.5 \mathrm{~s}$ and $0.9 \mathrm{~s}$, respectively. Wang et al. [2018] also estimated the natural period of high403 rise buildings as $0.34-0.65 \mathrm{~s}$ from their microtremor survey. The design spectra for these

There are various possibilities for the cause of the collapse of the buildings, such as construction deficiencies (e.g. antiquate building codes, soft story and rooftop additions ${ }_{410}$ indicated by [Lin et al., 2020a]), static offset at the fault, near-source ground motion. If 
${ }_{411}$ buildings do not have enough seismic capacity, damage caused by a moderate shaking can cause severe degradation, which significantly increases the natural period of the building

${ }_{413}$ during the shaking. To understand the cause of building collapse, the site specific ground

${ }_{414}$ motion estimation and structure response analysis are necessary. However, from our field

${ }_{415}$ survey, the linear site response was dominant near $1 \mathrm{~Hz}$, which did not explain the large ${ }_{416}$ pulse exceeding the design level.

\section{Conclusions}

We performed microtremor measurements in the Hualien basin in order to investigate ${ }_{418}$ the shallow subsurface soil structure and evaluate their effects on the ground motion and ${ }_{419}$ building damage during 2018 Hualien earthquake. We have three major conclusions which ${ }_{420}$ may contribute to the clarification of the large velocity pulse and building damage.

${ }_{421} 1$ ) Based on the inverted subsurface velocity structure, we found that the shallow subsur${ }_{422}$ face structure deepens from west to east and then becomes shallower at the Milun fault. ${ }_{423}$ The shallowing across the fault is consistent with the faulting during the mainshock and ${ }_{424}$ the long-term tectonic displacement. Due to this offset structure across the fault, the ${ }_{425}$ AVS30 of the west side of the fault is generally smaller than that of the east side of the ${ }_{426}$ fault.

2) Our survey results show that there is no significant difference in the shallow structure

${ }_{428}$ at the southern end of the Milun fault, where very large peak-to-peak velocity over $2 \mathrm{~m} / \mathrm{s}$ ${ }_{429}$ was recorded. This large amplitude $3 \mathrm{~s}$ pulse was probably generated by a source effect, ${ }_{430}$ rather than subsurface soil amplification.

$\left.{ }_{431} 3\right)$ As a result of the dense measurements in the damaged area, the locations where three ${ }_{432}$ buildings totally collapsed had relatively large AVS30 values compared to the areas farther ${ }_{433}$ from the Meilun river. This suggests that the subsurface soil structure close to the river 
${ }_{434}$ is unexpectedly harder compared to farther from the river. To clarify the cause of the collapse of these buildings, we need further investigations on the building construction

${ }_{436}$ and earthquake source characteristics.

\section{Data and Resources}

We used the seismic waveform data recorded by the CWB and the P-Alert Strong Motion Network. The data can be obtained from the website at https://gdms.cwb.gov.tw/ and https://palert.earth.sinica.edu.tw/index_e.php. The moment tensor mechanism of the 2018 Hualien earthquake is available at the USGS website (https:// earthquake.usgs.gov/earthquakes/eventpage/us1000chhc/executive). The PS logging data at the strong motion stations are availavle at Engineering Geological Database for TSMIP (http://egdt.ncree.org.tw/HWA_eng.htm).

The fault map in Hualien was obtained from: Hualien Prefecture Eastern Region Environmental Geology Research (http://geo.cpami.gov.tw/Case/97\%E8\%8A\%B1\%E8\%93\% AE $\%$ E7 $\%$ B8 $\%$ A3 $\%$ E8 $\% 8 F \% A F \% E 6 \% 9 D \% B 1 \% E 5 \% 9 C \% B 0 \% E 5 \% 8 D \% 80 \% E 7 \% 92 \% B 0 \% E 5 \% A 2 \% 83 \% E 5 \% 9 C \% B 0 \%$ E8\%B3\%AA $\%$ E7\%A0\%94\%E7\%A9\%B6.htm, in Chinese). The geology map in Hualien was obtained from the National Geological Data Warehouse (https://gis3.moeacgs.gov. tw/gwh/gsb97-1/sys8/t3/index1.cfm, this link is no longer available). Reconnaissance report of seismic damages provided by the NCREE (in Chinese) is available at (https://www.ncree.org/EarthquakeInfo/20180206/NCREE-2018-005F\%E5\% $8 \mathrm{~B} \% 98 \% \mathrm{E} 7 \% 81 \% \mathrm{BD} \% \mathrm{E} 5 \% \mathrm{AO} \% \mathrm{~B} 1 \% \mathrm{E} 5 \% 91 \% 8 \mathrm{~A}$.pdf).

We used an analysis code "TremorDataView" [Senna and Fujiwara, 2008] for the joint inversion of velocity structures. The code used to determine observed phase velocities was a modified version of Cho et al. [2008]. The code is available at https://staff .aist. go.jp/ikuo-chou/bidodl_en.html (last accessed February 2020). Some plots were made 
${ }_{457}$ using the Generic Mapping Tools version 4.5.7 [Wessel and Smith, 1991]. All websites were

${ }_{458}$ last accessed February 2020.

${ }_{459}$ We have two Supplemental Figures in the Supplemental Material.

\section{Acknowledgements}

We thank the CWB and the P-Alert Strong Motion Network for providing seismic waveform data. The filed survey was supported by the international research collaboration

${ }_{462}$ funding in Kyoto university and the NTU-KU faculty exchange program. We acknowledge

Dr. Tatsuya Noguchi in Tottori University for the use of their instruments.

\section{References}

${ }_{464}$ Aki, K. (1957). Space and time spectra of stationary stochastic waves, with special reference to microtremors. Bull. Earthq. Res. Inst. Univ. Tokyo, 35:415-456.

${ }_{466}$ Albarello, D. and Gargani, G. (2010). Providing NEHRP soil classification from the ${ }_{467}$ direct interpretation of effective Rayleigh-wave dispersion curves. Bull. Seism. Soc. Am., 100(6):3284-3294. 
${ }_{478}$ Bard, P.-Y., Acerra, C., Aguacil, G., Anastasiadis, A., Atakan, K., Azzara, R., Basili, R., Bertrand, E., Bettig, B., Blarel, F. et al. (2008). Guidelines for the implementation of

the $\mathrm{H} / \mathrm{V}$ spectral ratio technique on ambient vibrations measurements, processing and interpretation. Bull. Earthq. Eng., 6:1-2.

Bendat, J. S. and Piersol, A. G. (2010). Random data: analysis and measurement procedures. John Wiley \& Sons.

Boore, D. M., Joyner, W. B., and Fumal, T. E. (1993). Estimation of response spectra and peak accelerations from western North American earthquakes: An interim report. U.S. Geol. Surv. Open-File Rept. 93-509.

Brown, L., Diehl, J. G., and Nigbor, R. L. (2000). A simplified procedure to measure average shear-wave velocity to a depth of 30 meters (VS30). Proceedings of 12th World Conf. Earthq. Eng..

Cho, I. (2020). Two-sensor microtremor SPAC method: potential utility of imaginary spectrum components. Geophys. J. Int., 220(3):1735-1747.

Cho, I. and Iwata, T. (2019). A Bayesian approach to microtremor array methods for estimating shallow $\mathrm{S}$ wave velocity structures: Identifying structural singularities. $J$. Geophys. Res. Solid Earth, 124(1):527-553.

Cho, I., Tada, T., and Shinozaki, Y. (2004). A new method to determine phase velocities of Rayleigh waves from microseisms. Geophysics, 69:1535-1551.

Cho, I., Tada, T., and Shinozaki, Y. (2008). A new method of microtremor exploration using miniature seismic arrays: quick estimation of average shear velocities of the shallow soil. Butsuri-Tansa (Geophysical Exploration), 61:457-468. (in Japanese with English abstract).

Cho, I., Senna, S., and Fujiwara, H. (2013). Miniature array analysis of microtremors. Geophysics, 78(1):KS13-KS23. 
Ekström, G., Abers, G. A., and Webb, S. C. (2009). Determination of surface-wave phase velocities across USArray from noise and Aki's spectral formulation. Geophys. Res. Lett., 36(18):L18301.

Foti, S., Hollender, F., Garofalo, F., Albarello, D., Asten, M., Bard, P. Y., Comina, C., Cornou, C., Cox, B., Di Giulio et al. (2018). Guidelines for the good practice of surface wave analysis: a product of the InterPACIFIC project. Bull. Earthq. Eng., 16(6):23672420.

Fujimoto, K. and Midorikawa, S. (2006). Relationship between average shear-wave velocity and site amplification inferred from strong motion records at nearby station pairs. Journal of Japan Association for Earthquake Engineering, 6(1):11-22. (in Japanese).

Gardner, G., Gardner, L., and Gregory, A. (1974). Formation velocity and density - the diagnostic basics for stratigraphic traps. Geophysics, 39(6):770-780.

Haskell, N. A. (1960). Crustal reflection of plane SH waves. J. of Geophys. Res. (18961977), 65(12):4147-4150.

Hong, L. and Hwang, W. (2000). Empirical formula for fundamental vibration periods of reinforced concrete buildings in Taiwan. Earthq. Eng. and Struct. Dyn., 29(3):327-337.

Hsiao, C. P., Yeh, H. H., Sheu, M. S., Tsai, K. C., and Ding, Y. Q. (1999). General Report on Damage in Chi-Chi Earthquake - Damage Investigation for Building Structures. NCREE Research Report (No. NCREE-99-054). National Center for Research on Earthquake Engineering, Taiwan.

Huang, M. and Huang, H. (2018). The complexity of the 2018 Mw 6.4 Hualien earthquake in east Taiwan. Geophys. Res. Lett., 45(24):13,249-13,257.

Huang, S.-Y., Yen, J.-Y., Wu, B.-L., Yen, I.-C., and Chuang, R. Y. (2019). Investigating the Milun fault: The coseismic surface rupture zone of the 2018/02/06 $\mathrm{M}_{L} 6.2$ Hualien earthquake, Taiwan. Terr. Atmos. Ocean. Sci., 30(3):311-335. 
Kawase, H. (1996). The cause of the damage belt in Kobe:" The basin-edge effect," constructive interference of the direct S-wave with the basin-induced diffracted/Rayleigh waves. Seismo. Res. Lett., 67(5):25-34.

Konno, K. and Kataoka, S. (2000). An estimating method for the average S-wave velocity of ground from the phase velocity of Rayleigh wave. Trans. Jpn. Soc. Civ. Eng., 2000(647):415-423.

Konno, K. and Ohmachi, T. (1998). Ground-motion characteristics estimated from spectral ratio between horizontal and vertical components of microtremor. Bull. Seism. Soc. Am., 88(1):228-241.

Kuo, C.-H., Wen, K.-L., Hsieh, H.-H., Lin, C.-M., Chang, T.-M., and Kuo, K.-W. (2012). Site classification and VS30 estimation of free-field TSMIP stations using the logging data of egdt. Engineering Geology, 129:68-75.

Kuo, K., Hsieh, P., Xu, S., and Lin, S. (2018). Preliminary analysis on damage of building structures and interior space in the 20180206 Hualien earthquake. The 14th National Conference on Structural Engineering, Paper No. 24002. (in Chinese).

Kuo, C.-H., Huang, J.-Y., Lin, C.-M., Hsu, T.-Y., Chao, S.-H., and Wen, K.-L. (2019). Strong ground motion and pulse-like velocity observations in the near-fault region of the 2018 mw 6.4 hualien, taiwan, earthquake. Seismo. Res. Lett., 90(1):40-50.

Kuo-Chen, H., Guan, Z., Sun, W., Jhong, P., and Brown, D. (2019). Aftershock sequence of the 2018 Mw 6.4 Hualien earthquake in eastern Taiwan from a dense seismic array data set. Seismo. Res. Lett., 90(1):60-67.

Lee, S., Lin, T., Liu, T., and Wong, T. (2019). Fault-to-fault jumping rupture of the 2018 Mw 6.4 Hualien earthquake in eastern Taiwan. Seismo. Res. Lett., 90(1):30-39.

Lin, Y.-S., Chuang, R. Y., Yen, J.-Y., Chen, Y.-C., Kuo, Y.-T., Wu, B.-L., Huang, S.-Y., and Yang, C.-J. (2019). Mapping surface breakages of the 2018 Hualien earthquake by 
using UAS photogrammetry. Terr. Atmos. Ocean. Sci., 30(3):351-366.

Lin, J.-L., Kuo, C.-H., Chang, Y.-W., Chao, S.-H., Li, Y.-A., Shen, W.-C., Yu, C.-H., Yang, C.-Y., Lin, F.-R., Hung, H.-H., et al. (2020). Reconnaissance and learning after the February 6, 2018, earthquake in Hualien, Taiwan. Bull. Earthq. Eng., 18:4725-4754.

Lin, Y.-Y., Kanamori, H., Zhan, Z., Ma, K.-F., and Yeh, T.-Y. (2020). Modeling of pulse-like velocity ground motion during the $2018 \mathrm{Mw} 6.3$ Hualien earthquake, Taiwan. Geophys. J. Int., 223(1):348-365.

Ling, S. and Okada, H. (1993). An extended use of the spatial autocorrelation method for the estimation of geological structure using microtremors. Proceedings of the 89th SEGJ Conference, 44-48. (in Japanese).

Lo, C.-L., Chang, E. T.-Y., and Chao, B. F. (2012). Relocating the historical 1951 Hualien earthquake in eastern Taiwan based on tide gauge record. Geophys. J. Int., 192(2):854-860.

Lo, Y.-C., Yue, H., Sun, J., Zhao, L., and Li, M. (2019). The 2018 Mw6.4 Hualien earthquake: Dynamic slip partitioning reveals the spatial transition from mountain building to subduction. Earth Planet. Sci. Lett., 524:115729.

Martin, A. J. and Diehl, J. G. (2004). Practical experience using a simplified procedure to measure average shear-wave velocity to a depth of 30 meters (VS30). Proceedings of 13th World Conf. Earthq. Eng..

Midorikawa, S. (1994). Site effects on strong-motion records observed during the 1987 Chiba-ken-toho-oki, Japan earthquake. Proc. Ninth Japan Earthq. Eng. Symposium, 1994, 3:85-90.

Miyakoshi, K., Matsumoto, Y., Yamada, M., Mori, J., Cho, I., Hayashida, T., Kuo, C.-H., Lin, C.-M., Yen, Y.-T., Kuo., K.-C. et al. (2019). Estimation of Underground Structures around Source Area of the 2018 Hualien Earthquake (Mw 6.4) using Microtremor Array 
Observations. Proceedings of the Fall meeting of the Seismological Society of Japan, Kyoto, Japan, 2019.9.

Nakamura, Y. (1989). A method for dynamic characteristics estimation of subsurface using microtremor on the ground surface. Railway Technical Research Institute, Quarterly Reports, 30(1):25-33.

Okamoto, T., Kokusho, T., Nishi, K., Tanaka, Y., Kudo, K., Suzuki, K., Kawai, T., Sawada, Y., Ueshima, T., Kataoka, T., Yajima, H., Ikemi, M., and Higashi, S. (1998). Large-scale seismic test research at Hualien site in Taiwan - results of site investigation and characterization of foundation ground. Central Research Institute of Electric Power Industry (CRIEPI) Research Report, U97062 (in Japanese).

Parolai, S., Picozzi, M., Richwalski, S. M., and Milkereit, C. (2005). Joint inversion of phase velocity dispersion and $\mathrm{H} / \mathrm{V}$ ratio curves from seismic noise recordings using a genetic algorithm, considering higher modes. Geophys. Res. Lett., 32(1):L01303.

Picozzi, M., Parolai, S., and Richwalski, S. M. (2005). Joint inversion of H/V ratios and dispersion curves from seismic noise: Estimating the S-wave velocity of bedrock. Geophys. Res. Lett., 32(11):L11308.

Senna, S. and Fujiwara, H. (2008). Development of analyzing tools for microtremor survey observation data, vol. 1. Technical Note of the National Research Institute for Earth Science and Disaster Prevention, 313.

Shin, T.-C., Chang, C.-H., Pu, H.-C., Hsiao-Wei, L., and Leu, P.-L. (2013). The geophysical database management system in Taiwan. Terr. Atmos. Ocean. Sci., 24(1):11.

Shyu, J. B. H., Chen, C.-F., and Wu, Y.-M. (2016). Seismotectonic characteristics of the northernmost Longitudinal Valley, eastern Taiwan: Structural development of a vanishing suture. Tectonophysics, 692:295-308. 
$\mathrm{X}-28$ YAMADA ET AL: SHALLOW SUBSURFACE STRUCTURE IN HUALIEN BASIN

${ }_{602}$ Tomioka, T. and Yamamoto, S. (2006). Development of low noise accelerometer (JA40GA). JAE Technical Report, (29):122-129 (in Japanese).

Wang, X., Si, H., Koketsu, K., Nagano, M., and Dang, J. (2018). Building damage, strong ground motion characteristics and indoor damage of high-rise buildings in 2018 Hualien earthquake, Taiwan. Proceedings of the 15th Japan Earthquake Engineering Symposium, PS1-01-38 (in Japanese).

Wen, Y.-Y., Wen, S., Lee, Y.-H., and Ching, K.-E. (2019). The kinematic source analysis for 2018 Mw 6.4 Hualien, Taiwan earthquake. Terr. Atmos. Ocean. Sci., 30:1-11.

Wessel, P. and Smith, W. (1991). Free software helps map and display data. Eos, $72(441): 445-446$.

Wu, B.-L., Yen, J.-Y., Huang, S.-Y., Kuo, Y.-T., and Chang, W.-Y. (2019a). Surface deformation of 0206 Hualien earthquake revealed by the integrated network of RTK GPS. Terr. Atmos. Ocean. Sci., 30(3):301-310.

Wu, Y.-M., Mittal, H., Huang, T.-C., Yang, B. M., Jan, J.-C., and Chen, S. K. (2019b). Performance of a low-cost earthquake early warning system (P-Alert) and shake map production during the 2018 Mw 6.4 Hualien, Taiwan, earthquake. Seismo. Res. Lett., $90(1): 19-29$.

Yu, S.-B., Chen, H.-Y., and Kuo, L.-C. (1997). Velocity field of GPS stations in the Taiwan area. Tectonophys., 274(1-3):41-59. 
Table 1. Initial velocity structure for the inversion. The layer number, thickness, density,

$\mathrm{P}$-wave velocity, and S-wave velocity from the left.

\begin{tabular}{ccccc}
\hline No & $\Delta \mathrm{H}(\mathrm{m})$ & $\rho\left(\mathrm{g} / \mathrm{cm}^{3}\right)$ & $\mathrm{Vp}(\mathrm{m} / \mathrm{s})$ & $\mathrm{Vs}(\mathrm{m} / \mathrm{s})$ \\
\hline \hline 1 & 8 & 1.59 & 700 & 200 \\
2 & 30 & 1.90 & 1400 & 300 \\
3 & 30 & 2.02 & 1800 & 350 \\
4 & 100 & 2.10 & 2100 & 600 \\
5 & - & 2.17 & 2400 & 1000 \\
\hline
\end{tabular}




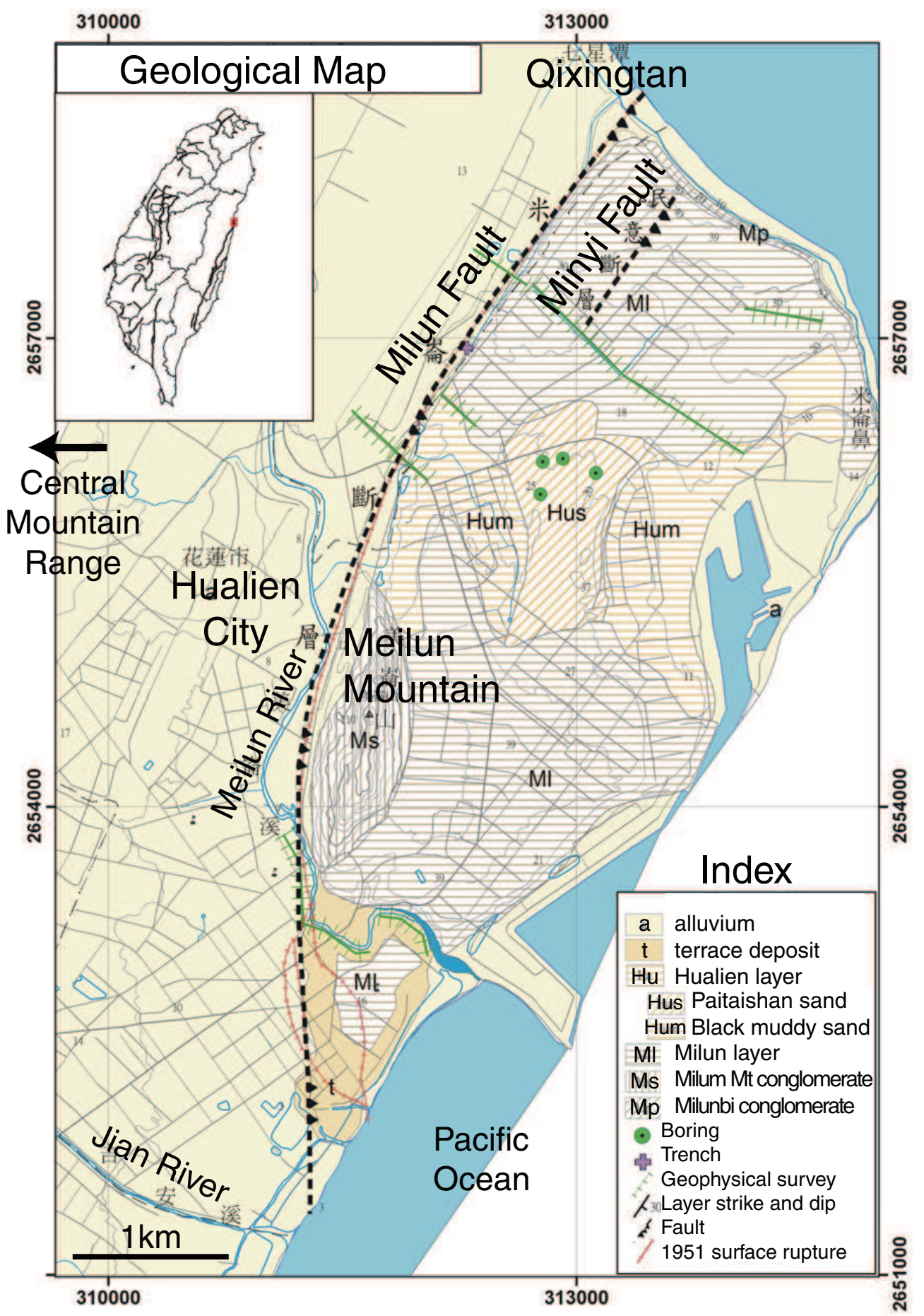

Figure 1. Geological map of the Hualien (modified after the Geological Map provided by Central Geological Survey, Taiwan. See Data and Resources Section). The coordinate system is TWD67 TM2. 


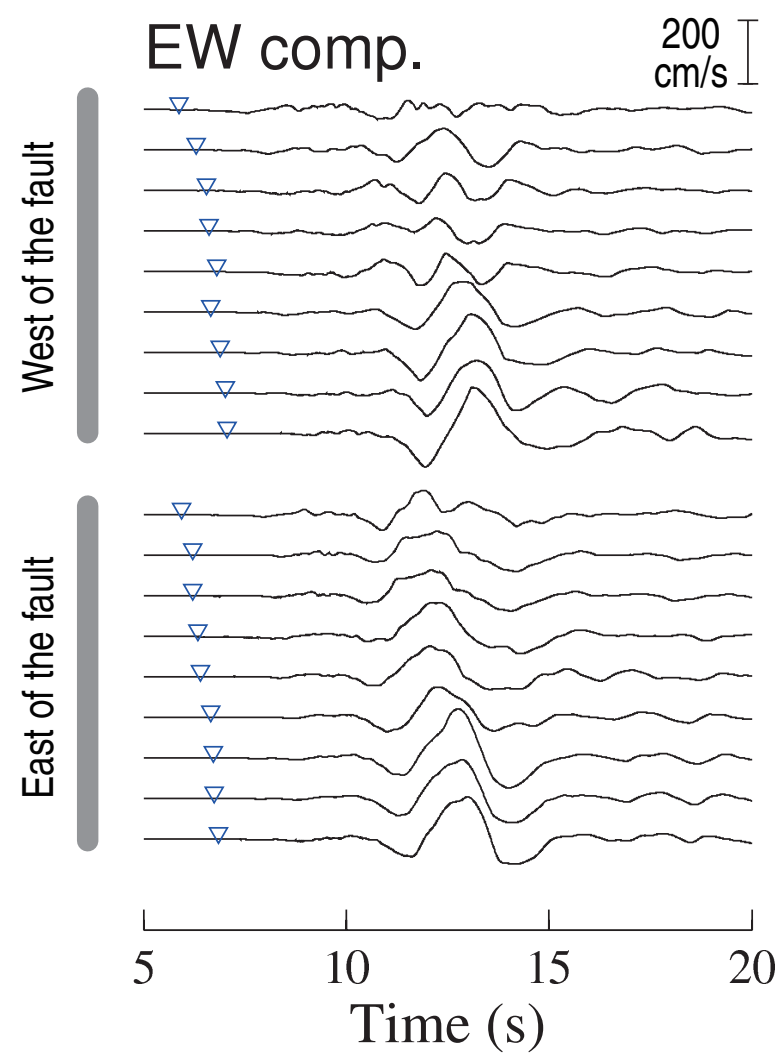

\section{NS comp.}

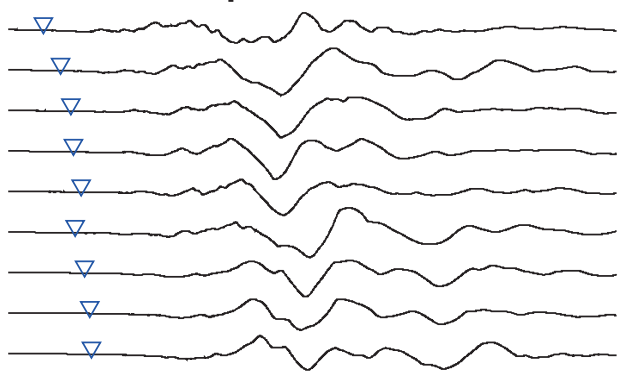

HWA028

TRB042

HWA011

HWA063

HWA050

HWA008

HWA010

HWA013

HWA014

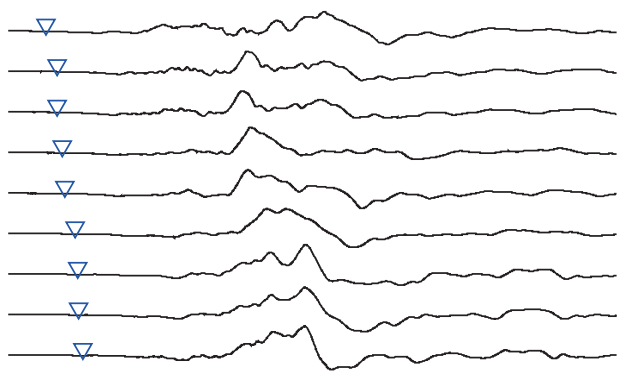

WOOE

W002

HWA012

HWA009

HWA007

HWA062

W028

WOOF

HWA019

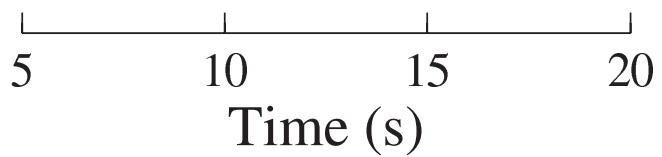

Figure 2. Velocity waveforms on the west and east sides of the fault from north to south. The inverted triangles show the theoretical S-wave arrival time. The horizontal axis shows the time after the origin time. 


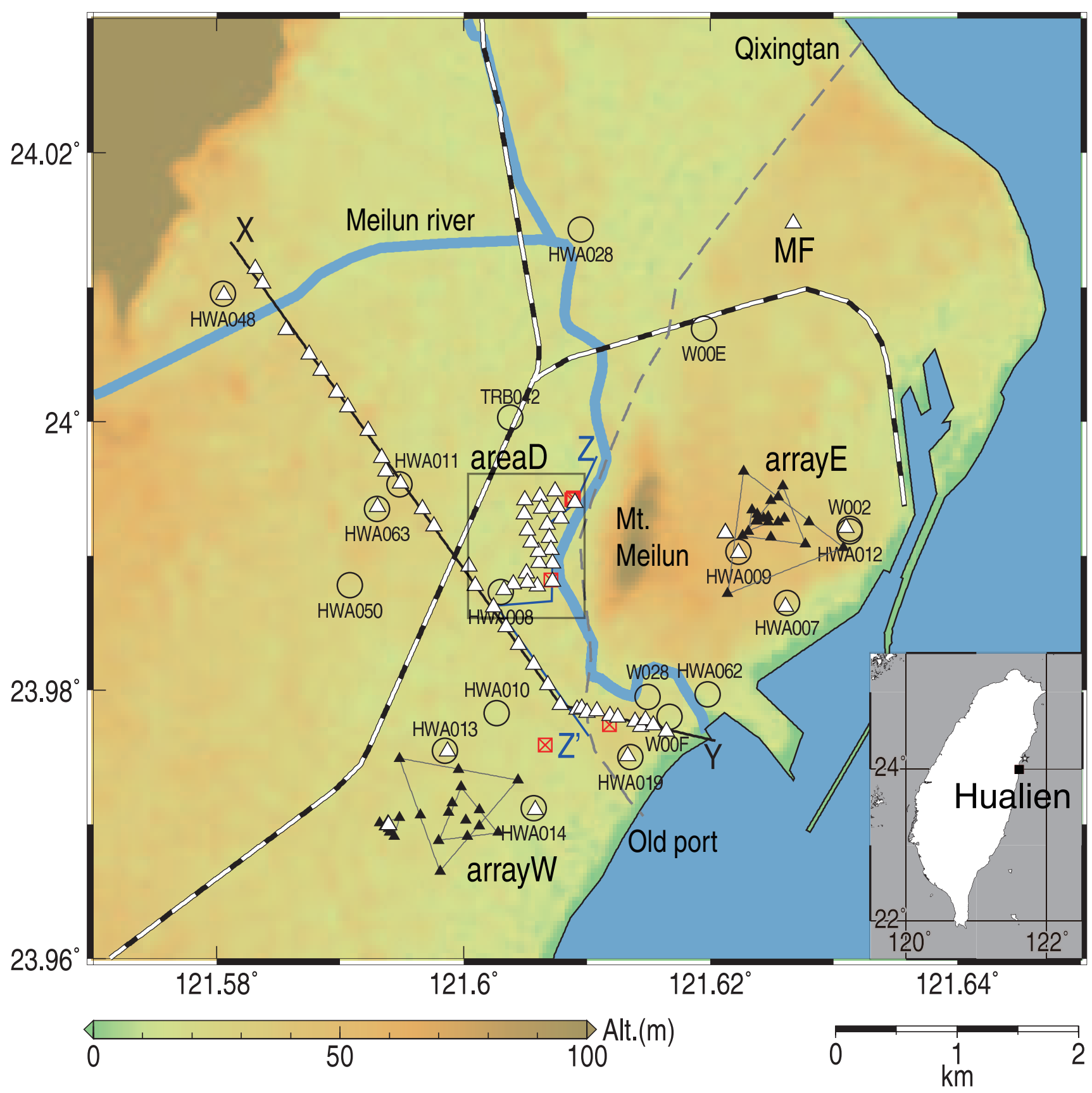

Figure 3. Map of the measurement locations. Open triangles show the locations of small arrays, and solid triangles show the locations of large arrays (array E and array W). Open circles show the locations of strong motion stations. Square symbols with a cross inside show the location of the heavily damaged buildings. Background color shows the altitude. The broken gray line shows the location of the Milun fault [Huang and Huang, 2018]. The railway is shown by a black and white line. 
(a)

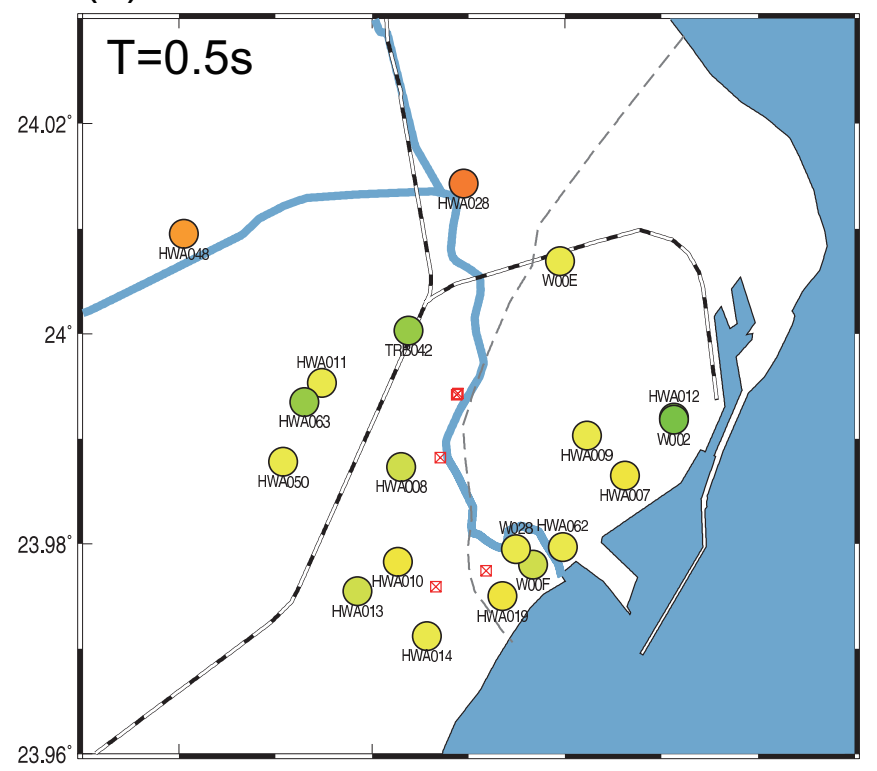

(c)

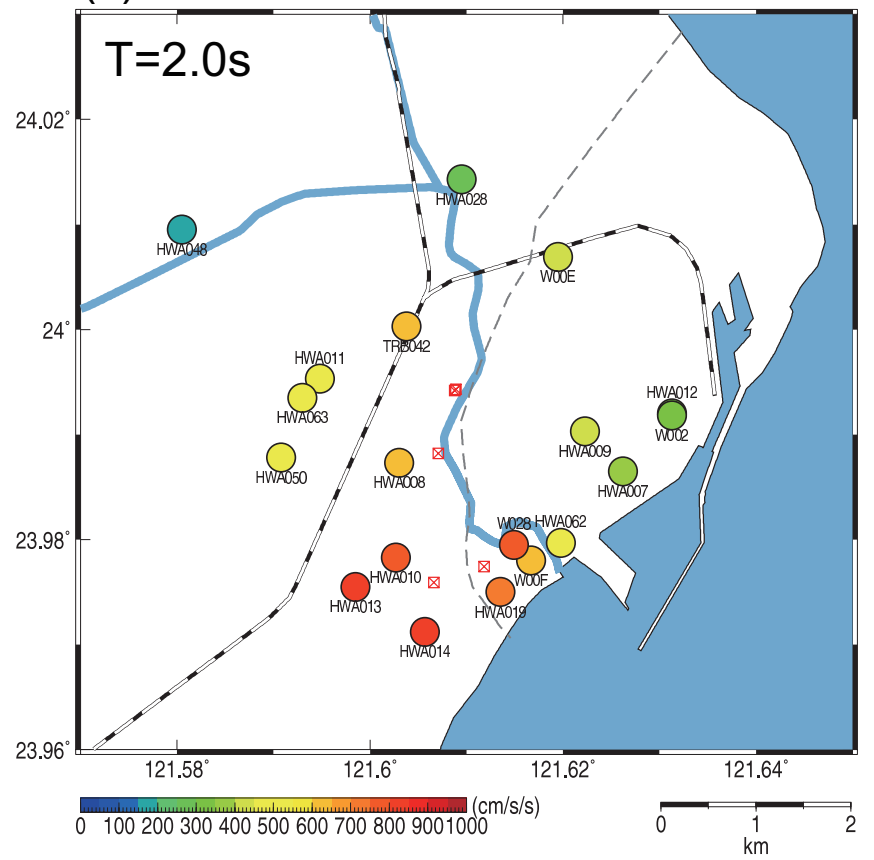

(b)

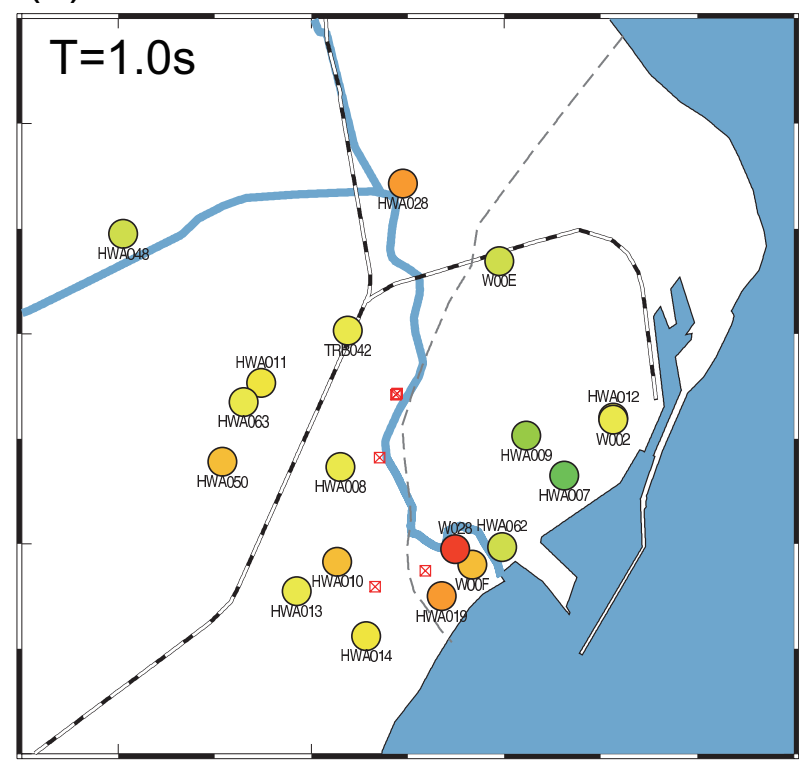

(d)

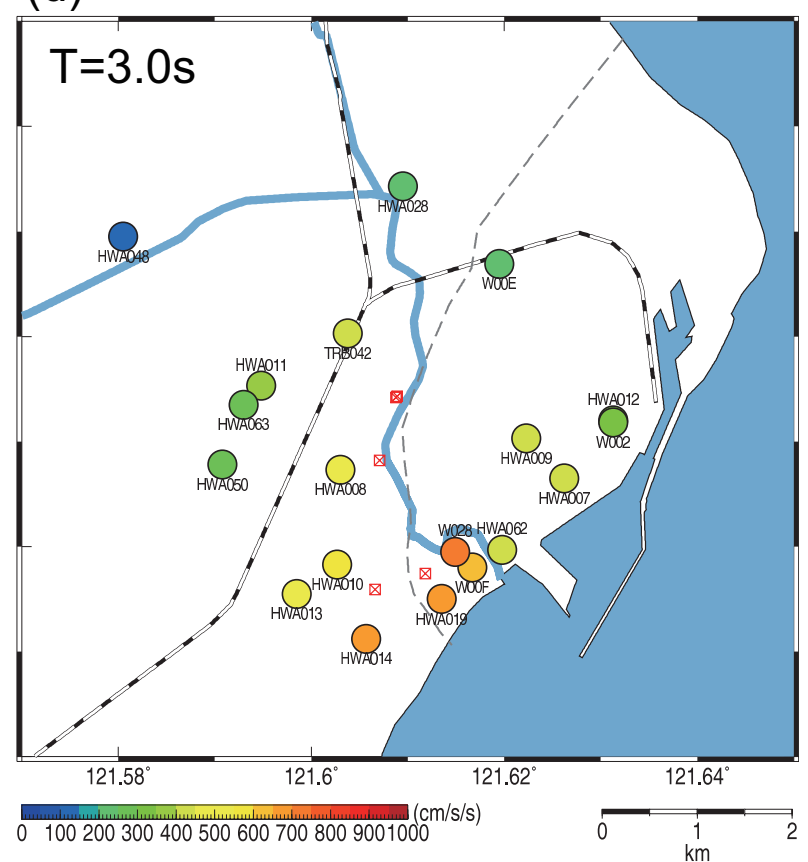

Figure 4. Acceleration response spectra for the EW component during the mainshock at the period of (a) $0.5 \mathrm{~s}$, (b) $1.0 \mathrm{~s}$, (c) $2.0 \mathrm{~s}$, and (d) $3.0 \mathrm{~s}$. The damping is $5 \%$. Other symbols are in the same format as Figure 3. 
(a)

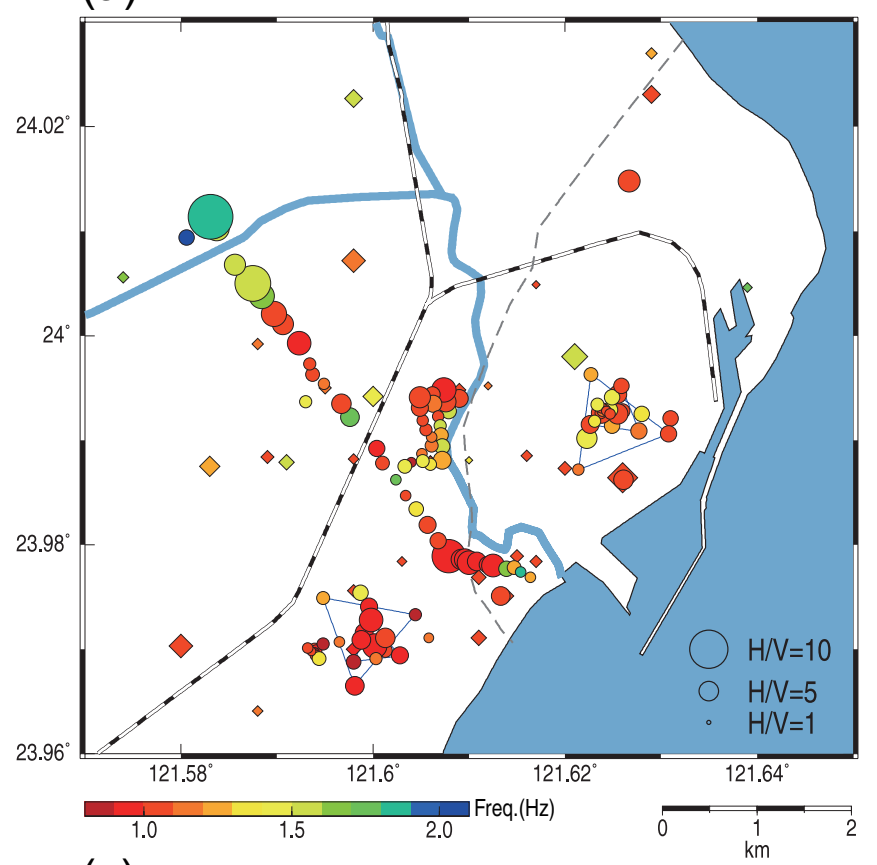

(c)

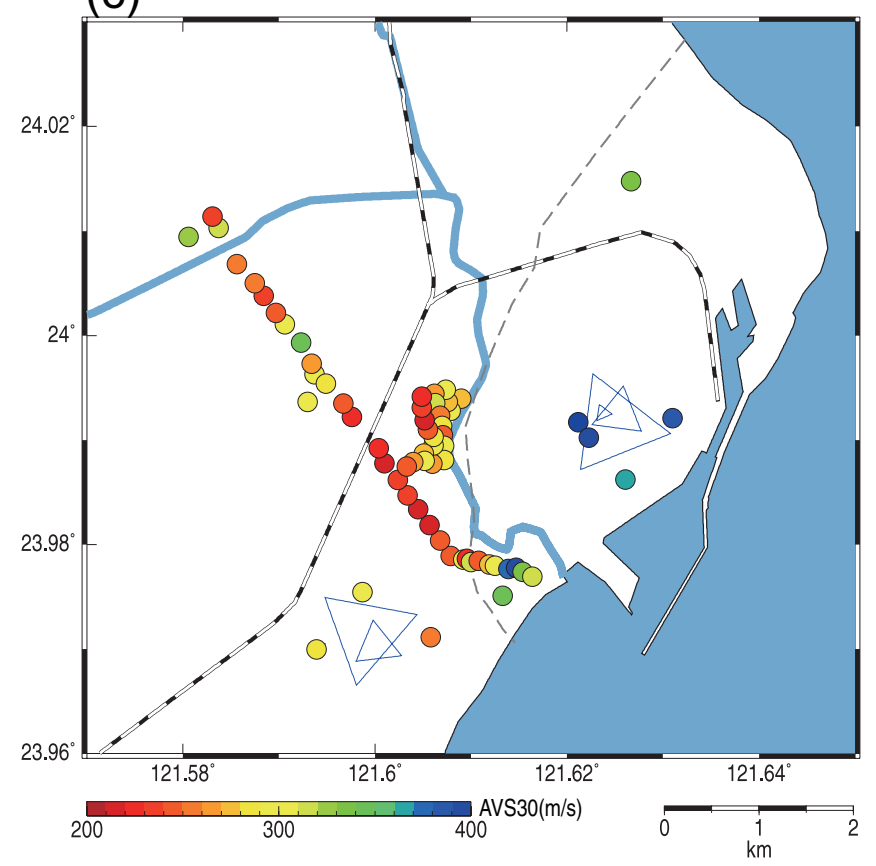

(b)

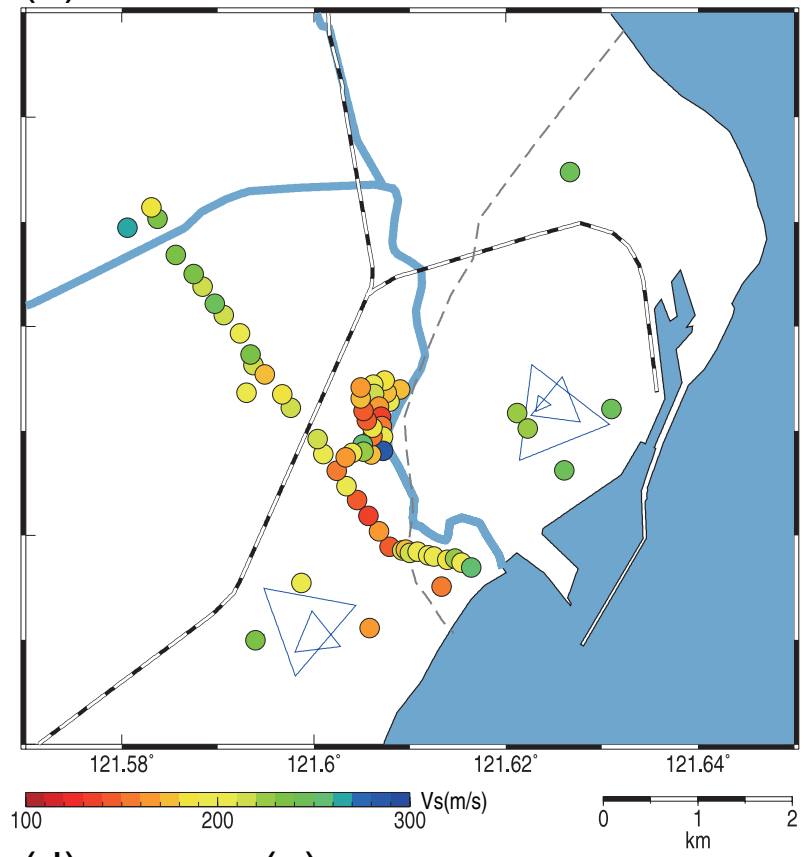

(d)

(e)

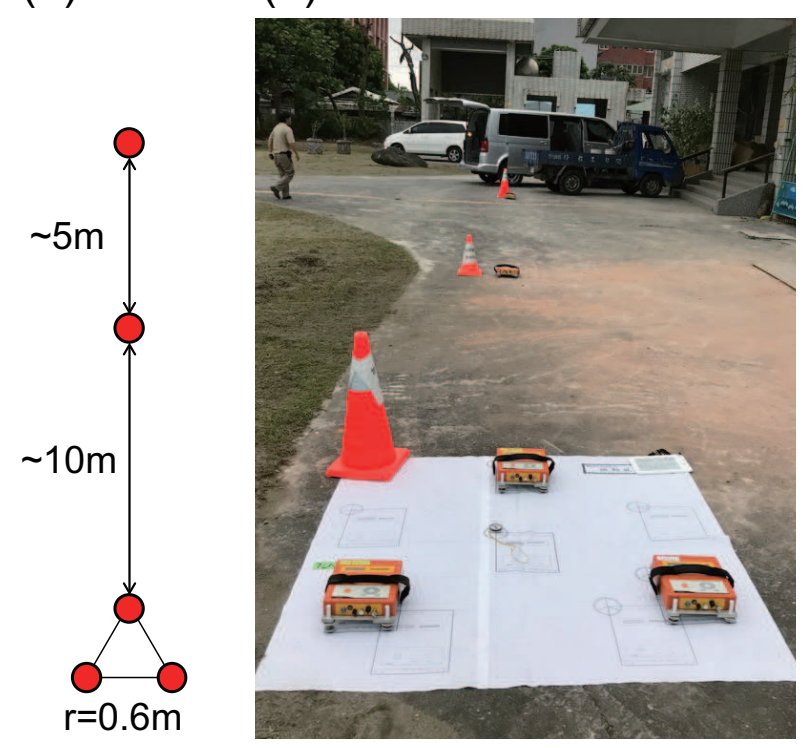

Figure 5. (a) Peak amplitudes and frequencies of the H/V spectrum. The size and color of the symbols show the peak amplitude and peak frequency, respectively. The circles show the results of this study, and the diamonds show the result of NCREE report (see Data and Resources Section). (b) S-wave velocity of the shallowest layer estimated from the phase dispersion curve. (c) AVS30 directly estimated from the phase velocity curves. (d) Sensor geometry for the small array measurement. (e) Photo of the small array measurement. 


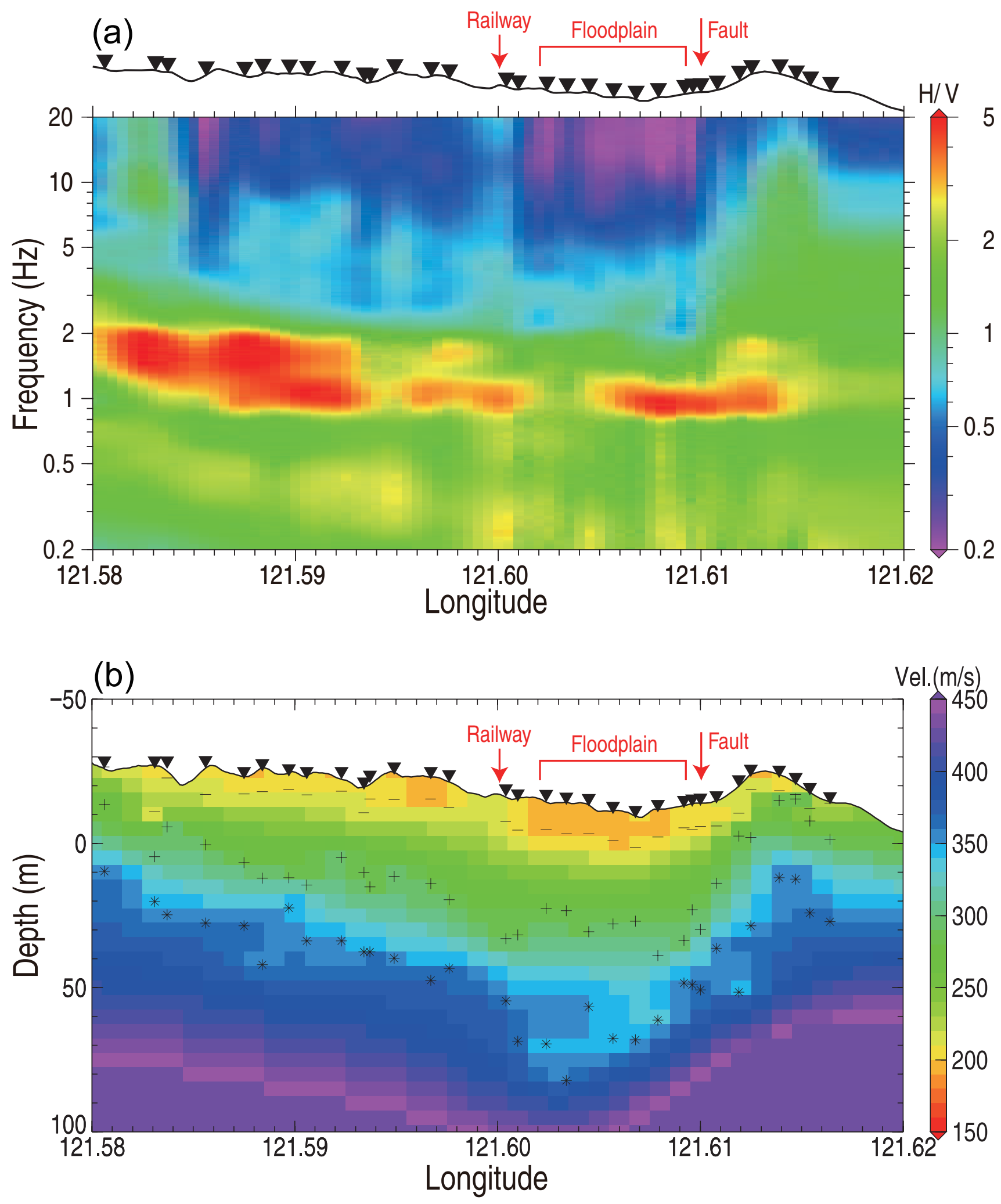

Figure 6. (a) H/V spectra along the X-Y section in Figure 3. The curves above the colored plots show the altitude and the triangles show the measurement location. (b) Inverted S-wave velocity structure along the X-Y section in Figure 3. Bars, crosses, and asterisks show the velocity structure boundary for the first, second and third layers, respectively. 
(a)

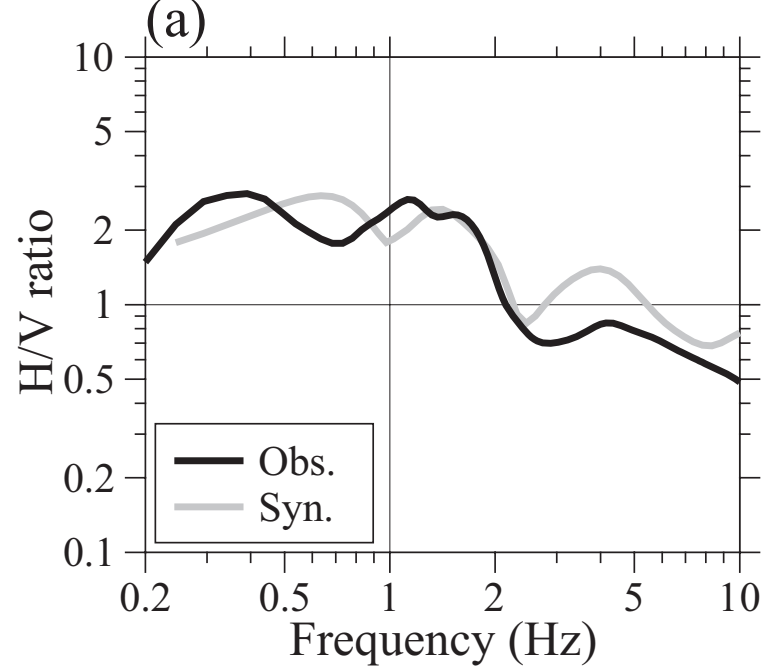

(b)

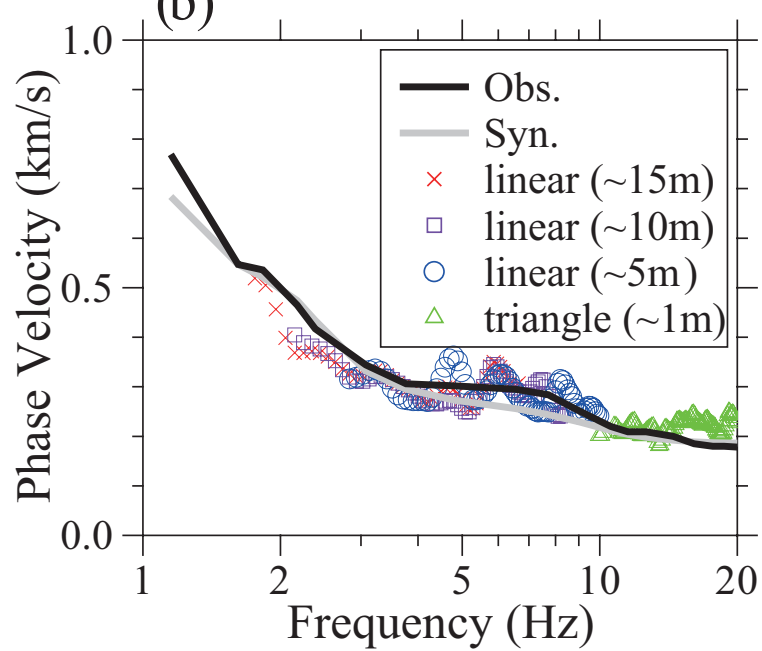

Figure 7. (a) Comparison between the observations (black) and synthetics (gray) for the $\mathrm{H} / \mathrm{V}$ spectra. (b) Comparison of observed (black) and synthetic (gray) phase velocity curves at the station HWA011. The individual curves for arrays with different sizes are also shown with symbols. The frequency ranges corresponding to the wavelength of $3-20$ times of the array radius are shown.

(a)

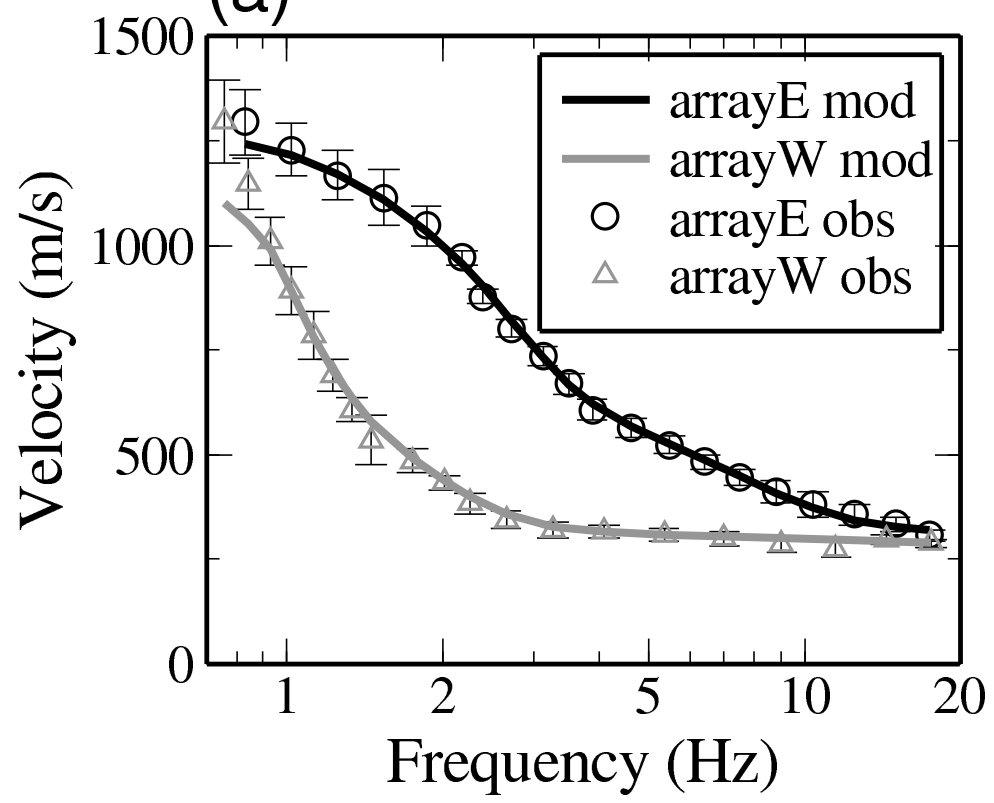

(b)

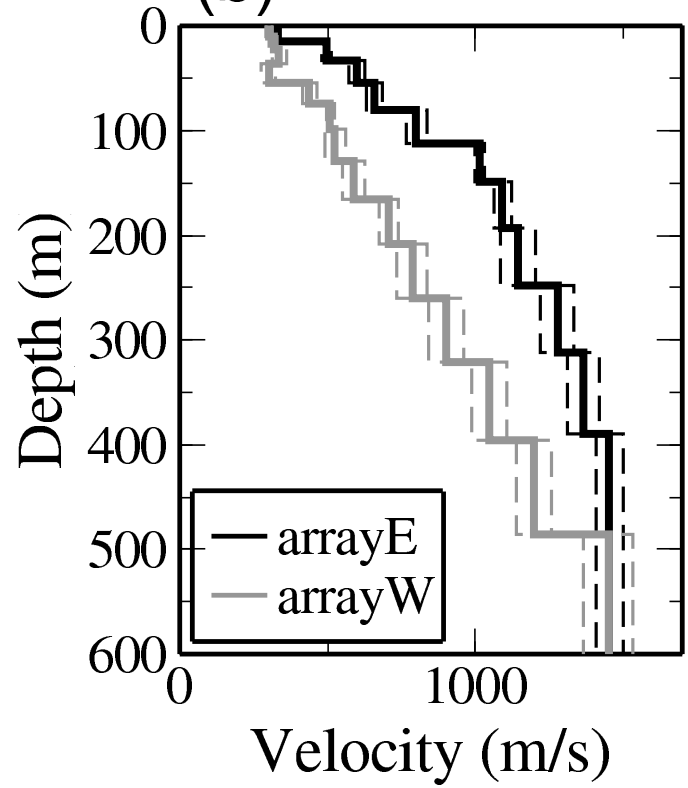

Figure 8. (a) Observed and estimated phase velocity curves for the large array E (black) and array W (gray). Errorbars for the observation are also shown. (b) Estimated velocity structure for the large array E (black) and array W (gray). Errors of the models are shown as thin dashed lines. 
(a)

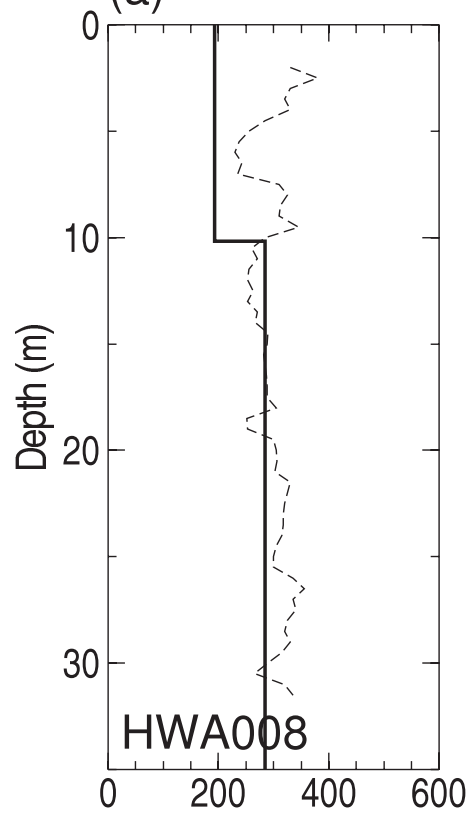

(e)

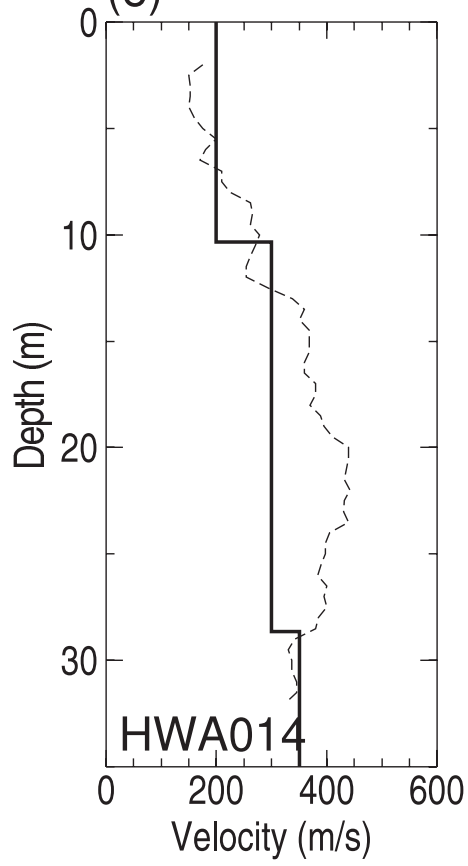

(b)

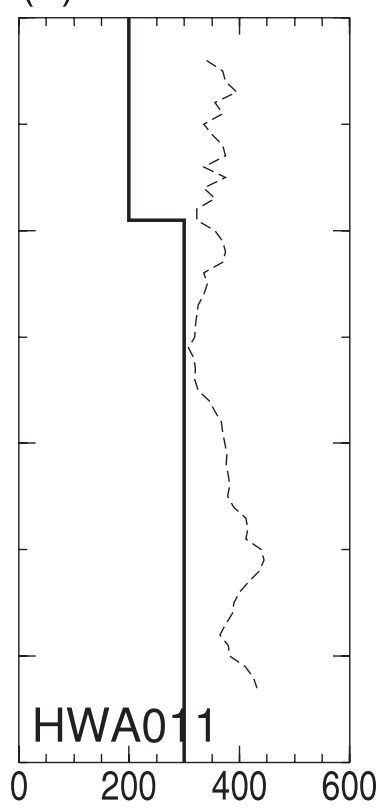

(f)

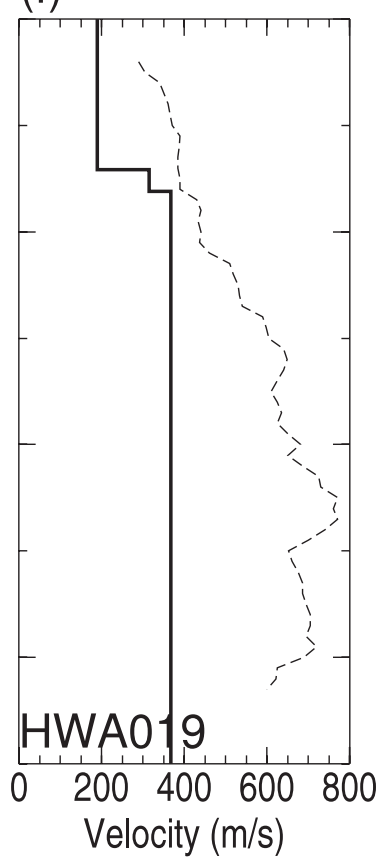

(c)

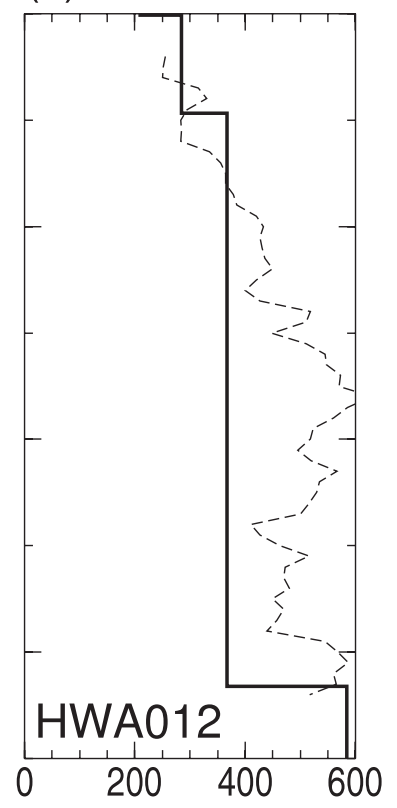

(d)

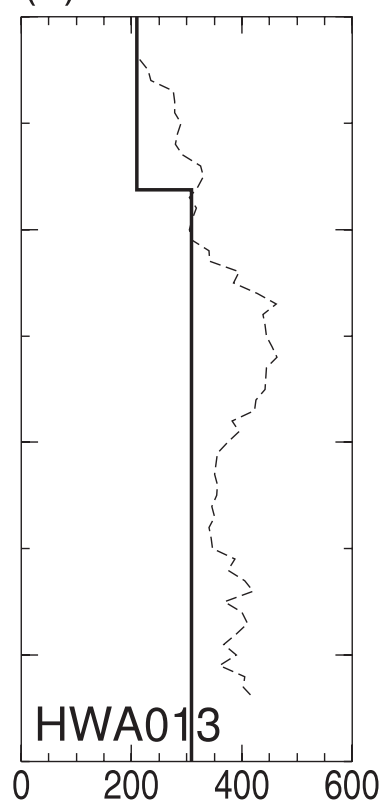

(g)

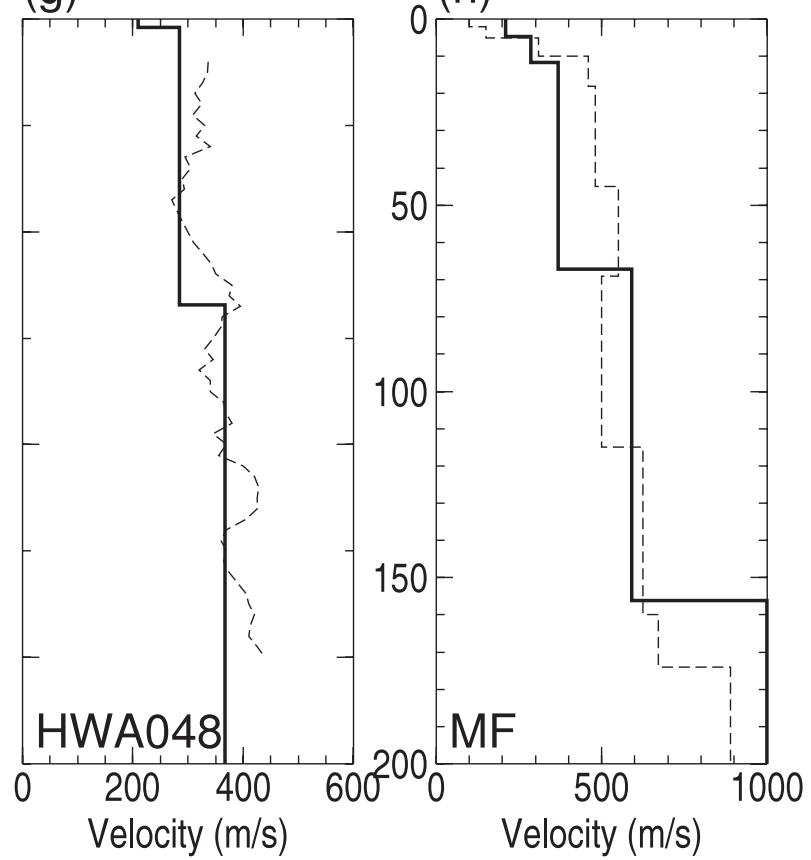

Figure 9. Velocity structures of the borehole logging data (dashed lines) and estimated velocity structures from the microtremor data (solid lines) at the strong motion stations: (a) HWA008, (b) HWA011, (c) HWA012, (d) HWA013, (e) HWA014, (f) HWA019, (g) HWA048, and (h) MF. 

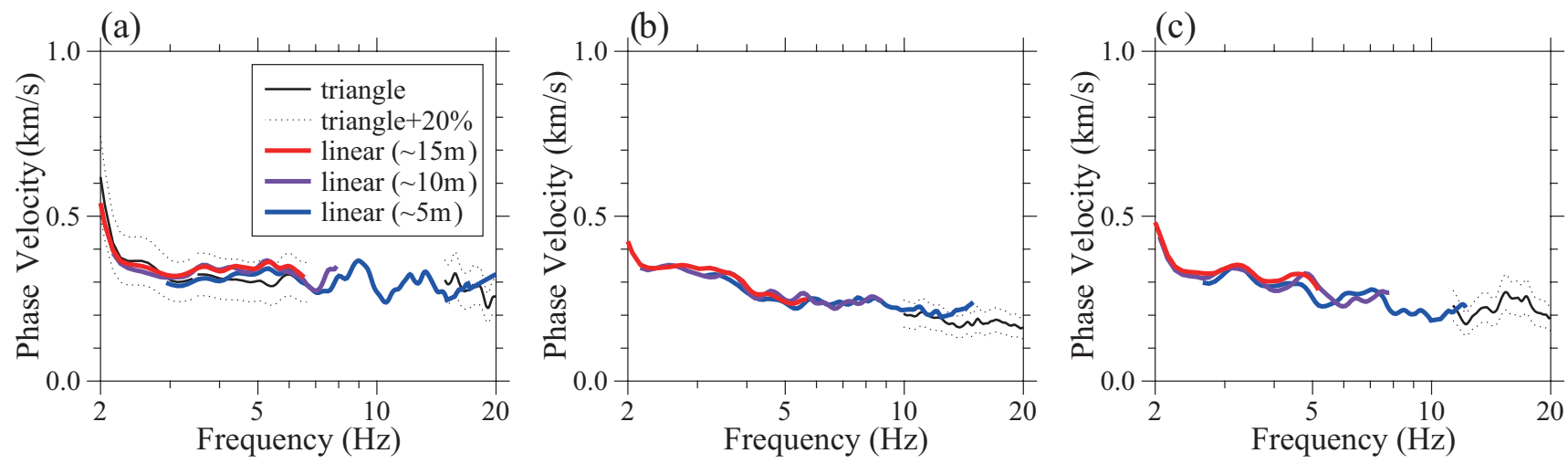

Figure 10. Observed phase velocity curves for the (a) large array W, (b) HWA008, and (c) HWA014. The thick black lines show the phase velocity curves estimated from the triangle array, and colored lines show those estimated from the linear array with two sensors. The broken lines show the range of $\pm 20 \%$ from the estimation.

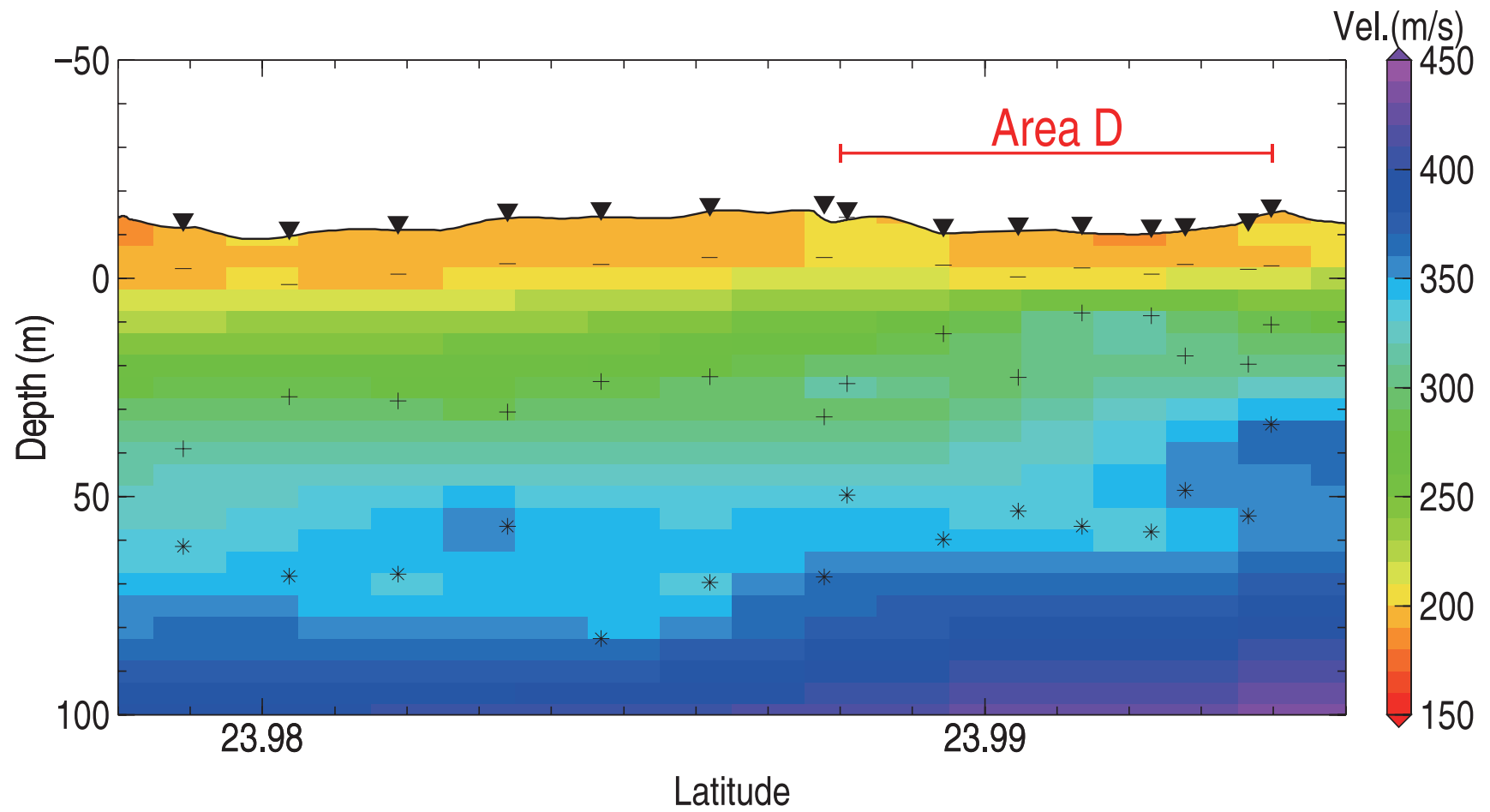

Figure 11. Inverted S-wave velocity structure along the Z-Z' section in Figure 3. The symbols are in the same format as Figure 6(b). 


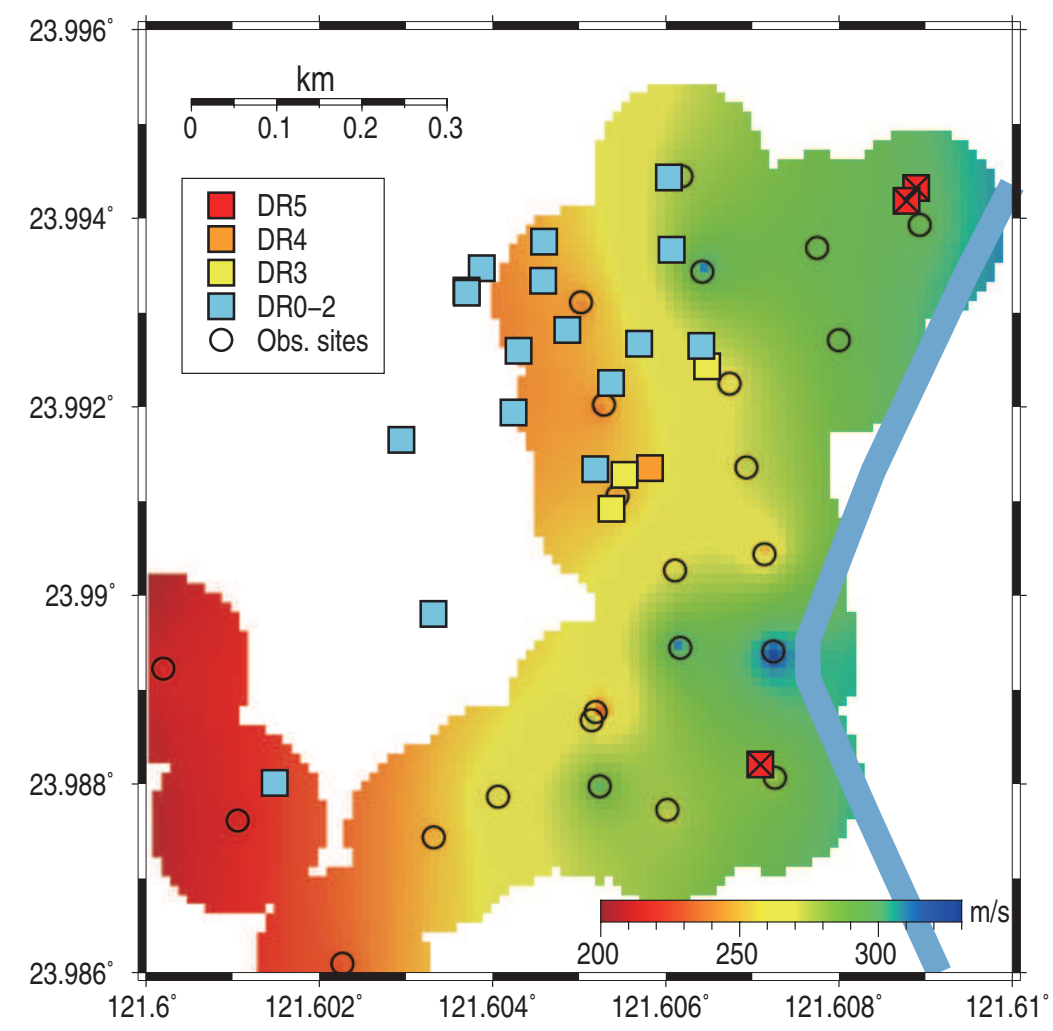

Figure 12. AVS30 (background color) and damage rank (square symbols) of the high-rise buildings in the heavily damaged area D. Open circles show the microtremor observation points. The thick line shows the Meilun river. 